\title{
Inflammation, Nitro-Oxidative Stress, Impaired Autophagy, and Insulin Resistance as a Mechanistic Convergence Between Arterial Stiffness and Alzheimer's Disease
}

\section{OPEN ACCESS}

Edited by:

Roberto Carnevale,

Sapienza University of Rome, Italy

Reviewed by:

Tanisha Singh,

University of Pittsburgh, United States

Simona Bartimoccia,

Sapienza University of Rome, Italy

${ }^{*}$ Correspondence:

Guido R. Y. De Meyer

guido.demeyer@uantwerpen.be

Jhana O. Hendrickx

jhana_h@hotmail.com

Specialty section:

This article was submitted to

Molecular Diagnostics

and Therapeutics,

a section of the journal

Frontiers in Molecular Biosciences

Received: 08 January 2021 Accepted: 03 March 2021

Published: 29 March 2021

Citation:

Hendrickx JO, Martinet W, Van Dam D and De Meyer GRY (2021) Inflammation, Nitro-Oxidative Stress,

Impaired Autophagy, and Insulin

Resistance as a Mechanistic

Convergence Between Arterial

Stiffness and Alzheimer's Disease.

Front. Mol. Biosci. 8:651215.

doi: 10.3389/fmolb.2021.651215

\begin{abstract}
Jhana O. Hendrickx'*, Wim Martinet ${ }^{1}$, Debby Van Dam ${ }^{2,3}$ and Guido R. Y. De Meyer ${ }^{1 *}$
1 Laboratory of Physiopharmacology, Faculty of Pharmaceutical, Biomedical and Veterinary Sciences, University of Antwerp, Antwerp, Belgium, ${ }^{2}$ Laboratory of Neurochemistry and Behavior, Institute Born-Bunge, Department of Biomedical Sciences, University of Antwerp, Antwerp, Belgium, ${ }^{3}$ Department of Neurology and Alzheimer Research Center, University

of Groningen and University Medical Center Groningen, Groningen, Netherlands
\end{abstract}

The average age of the world's elderly population is steadily increasing. This unprecedented rise in the aged world population will increase the prevalence of agerelated disorders such as cardiovascular disease (CVD) and neurodegeneration. In recent years, there has been an increased interest in the potential interplay between CVDs and neurodegenerative syndromes, as several vascular risk factors have been associated with Alzheimer's disease (AD). Along these lines, arterial stiffness is an independent risk factor for both CVD and AD. In this review, we discuss several inflammaging-related disease mechanisms including acute tissue-specific inflammation, nitro-oxidative stress, impaired autophagy, and insulin resistance which may contribute to the proposed synergism between arterial stiffness and AD.

Keywords: inflammaging, metabolism, nitro-oxidative stress, autophagy, neurodegeneration, arterial stiffness

\section{INTRODUCTION}

The average age of the world population is steadily increasing with approximately 1 billion people in 2019 that were aged 65 or older. By 2030, this number is estimated to increase to 1.4 billion, reaching 2.1 billion by 2050 (WHO, 2018). This unprecedented rise in the aged world population will increase the prevalence of age-related disorders such as cardiovascular disease (CVD) and dementia. Globally, CVD is the number one cause of death with an estimated mortality of 17.9 million people in 2016 (WHO, 2017). That same year, 43.8 million people worldwide suffered from dementia, which was the fifth leading cause of global death with 2.4 million people dying from this disease (GBD 2016 Neurology Collaborators, 2019). Historically, CVD and Alzheimer's disease (AD) were considered to be separate entities based on clinical classification criteria. However, increasing epidemiological studies report an independent convergence between both diseases, suggesting a mechanistic overlap. In this review, we discuss chronic low-grade inflammation as the mechanistic convergence between $\mathrm{CVD}$ and $\mathrm{AD}$ given its major contribution in both pathologies.

\section{Alzheimer's Disease}

For many centuries, dementia has been described in ancient texts (e.g., "Be kind to your father, even if his mind fails him." - Old Testament: Sirach 3:12). In itself, dementia comprises a plethora of neurological syndromes with the overall clinical symptom of a progressive cognitive disturbance affecting the patient's independent functionality in everyday life. These cognitive disturbances are commonly accompanied by changes in behavior, mood, and personality (Tariot et al., 1995; 
Mega et al., 1996). In the past, a distinction was often made between primary degenerative dementias, such as dementia with Lewy bodies, frontotemporal dementia, and AD. However, since The Lancet International Conference on Dementias in 1966 (Eastwood et al., 1996), the genesis of dementia syndromes was elucidated by reassessing this simplistic distinction as a complex synergism of (epi)genetic predisposition, lifestyle factors, psychosomatic, and neuropathological changes. Now it is clear that age is the overarching common factor, given the singular or additive effects of pathologies on dementia. Current diagnostic criteria for dementia incorporate advances in scientific knowledge and technological progression in the detection and understanding of dementia and related disorders associated with cognitive impairment. The most recent edition of the Diagnostic and Statistical Manual of Mental Disorders (DSM5) renamed dementia to major neurocognitive disorder (NCD), although the label dementia is still of course interchangeably used with major NCD. DSM-5 also distinguishes between major NCD and mild NCD, which is perhaps better known as mild cognitive impairment (MCI) or prodromal dementia (Vahia, 2013). Specifically, for AD, as the prototype of cortical dementia, the National Institute on Aging and Alzheimer's Association described separate diagnostic criteria and related recommendations for the preclinical, $\mathrm{MCI}$, and dementia stages of $\mathrm{AD}$, for the first time also considering in vivo biomarkers, based on neuroimaging and the determination of disease-linked compounds in bodily fluids (Jack et al., 2018).

The conceptualization of AD dates from 1907 when Alois Alzheimer reported the presence of neuropathological amyloid plaques and neurofibrillary tangles (NTFs) after the postmortem brain analysis of 55-year-old Auguste Deter (Maurer et al., 1997). Over the past decades, molecular biology and genetic research have led to an improved understanding of these two key neuropathological lesions. Additional lesions include cerebral amyloid angiopathy (CAA), dystrophic neurites, neuropil threads, astrogliosis, and microglial activation (SerranoPozo et al., 2011). As the most prominent form of dementia, AD accounts for an estimated $60-80 \%$ of dementia patients aged 65 or older (Alzheimer's Association, 2015). Most patients present with an anterograde amnestic syndrome besides retention of social graces due to mesial temporal lobe atrophy (McKhann et al., 2011; Orgeta et al., 2015). That is why the World Health Organization recognizes $\mathrm{AD}$ as a global public health priority. The vast majority of late-onset $\mathrm{AD}$ cases occur on a sporadic basis, driven by a complex combination of genetics and environmental factors of which $70 \%$ is thought to be attributable to genetics. While aging is still the biggest risk factor of lateonset $\mathrm{AD}$, genetic risk factors have also been identified. The most common genetic risk factor comprises polymorphisms in one of the three common alleles $(\varepsilon 2, \varepsilon 3$, and $\varepsilon 4)$ of the $A P O E$ gene of which mutations in the $\varepsilon 4$ allele carry to the most increased risk (Hardy, 1995; Verghese et al., 2011; AlzGene, 2020a). Because this $A P O E$ genotype is linked to cholesterol transport dynamics, it has been suggested that it is a vascular risk factor of late-onset $\mathrm{AD}$ (Kalaria et al., 2012). Besides polymorphisms in the APOE gene, several novel risk genes have been suggested which are linked to cholesterol metabolism (ABCA7), inflammation (TREM2), amyloid beta $(\mathrm{A} \beta)$ clearance $(C L U)$, the immune system $(C R 1)$ among others (AlzGene, 2020b). The less common early-onset $\mathrm{AD}$ cases are mostly attributable to inheritable mutations in the APP, MAPT, PSEN1, and PSEN2 gene (Haass and De Strooper, 1999; Bateman et al., 2011; AlzForum, 2020). Recently, age-dependent differences in mRNA expression levels of the aforementioned late-onset $\mathrm{AD}$ genetic risk factor, TREM2, have been found in early-onset $\mathrm{AD}$ cases. This finding indicates that the TREM2 gene might be a non-hereditary risk factor for earlyonset AD (Guven et al., 2020). Although advances in medical technology in the past have led to longer survival, there is still a lack of disease-modifying treatments.

\section{Amyloid Plaques}

One of the major pathological hallmarks of both early- and late-onset $\mathrm{AD}$ is the extracellular accumulation of abnormally folded $A \beta$ peptides in amyloid plaques. $A \beta$ peptides are 36-42 amino acids long proteolytic fragments derived from the transmembrane and extracellular domains of the amyloid precursor protein (APP), which localizes genetically on chromosome 21. APP can be processed via either the amyloidogenic pathway, thereby releasing $A \beta$ peptides after cleavage at both the $\gamma$-secretase and $\beta$-amyloid cleavage enzyme (BACE) sites, or via the non-amyloidogenic pathway in which $\alpha$-secretase cleaves within the $A \beta$ sequence to release a neuroprotective sAPP $\alpha$ fragment (Nunan and Small, 2000). Monomeric $\mathrm{A} \beta$ peptides tend to aggregate as oligomers, protofibrils, and mature amyloid fibrils. Amyloid plaques mainly constitute of $A \beta 1-40$ and $A \beta 1-42$ peptides with the latter type being most prone to aggregation into amyloid plaques (Hardy, 1997). Mutation clusters around the three secretase cleaving sites of APP are known to cause familial AD, with mutations leading to an increased production of total $A \beta$ or an increased $\mathrm{A} \beta 1-42 / \mathrm{A} \beta 1-40$ ratio (AlzForum, 2020).

Several types of plaques have been described ranging from diffuse plaques, being amorphous amyloid deposits, over densecore plaques with fibrillar amyloid deposits that are typically surrounded by dystrophic neurites (neuritic plaques), reactive astrocytes and activated microglial cells, and culminating into burnt-out plaques (Serrano-Pozo et al., 2011). Amyloid plaques primarily accumulate in the neocortex, often involving all six neocortical layers, continuing to the allocortex and finally also progressing to subcortical regions (Arnold et al., 1991; Thal et al., 2002). Various scoring systems have been implemented to stage amyloid plaque burden and spreading. Initially, three stages (A through C) were distinguished (Braak and Braak, 1991). Thal et al. (2002) proposed five stages (1 through 5) to describe the spatiotemporal progression of amyloid pathology.

\section{Cerebral Amyloid Angiopathy}

Apart from the parenchymal accumulation of $A \beta$, approximately $80-90 \%$ of $\mathrm{AD}$ patients also exhibit $\mathrm{A} \beta$ deposition in cerebrovascular vessels, referred to as CAA (Yamada et al., 1987; Yamada, 2002). CAA is mainly observed in leptomeningeal and cortical vessels (Yamada et al., 1987). In contrast to amyloid plaques, cerebrovascular $\mathrm{A} \beta$ segments are mainly 40 amino acids in length (Prelli et al., 1988; Suzuki et al., 1994). After neuronal 
release, $A \beta 1-42$ aggregates in amyloidogenic plaques in brain parenchyma, while $A \beta 1-40$ is transported via interstitial fluid drainage to the cerebrovasculature for clearance. In this process, A $\beta 1-40$ can aggregate on and deposit within cerebrovascular basement membranes (Weller et al., 1998). Affected vessels can show secondary vasculopathic changes, such as loss of smooth muscle cells, wall thickening, fibrinoid necrosis, formation of micro aneurysms, and deposition of perivascular blood breakdown products (Love et al., 2015).

\section{Neurofibrillary Tangles}

Neurofibrillary tangles (NFTs) are another neuropathological hallmark of the $\mathrm{AD}$ brain. The major components of the intracellular NFTs are paired helical filaments of hyperphosphorylated microtubule-associated protein tau (MAPT) (Serrano-Pozo et al., 2011). MAPT forms a crucial neuronal component via the assembly and stabilization of the microtubule cytoskeleton which is essential for axonal transport (Paglini et al., 2000). Cytoskeleton disassembly impairing axonal transport and aggregation of hyperphosphorylated tau into fibrils are early events of $\mathrm{AD}$ pathogenesis and significantly impact neuronal functioning (Nagy et al., 1995). The spatiotemporal distribution of tauopathy follows the reversed pattern to amyloid burden in $\mathrm{AD}$. Tau pathology in $\mathrm{AD}$ develops progressively in synaptically connected brain regions presumably based on transcellular propagation of tau aggregates (Furman et al., 2017). NFTs arise earliest in the entorhinal cortex and hippocampus located in the medial temporal lobe and further spread to the associative isocortex, thereby relatively exempting primary sensory, motor, and visual areas. NFTs exhibit a characteristic distribution pattern permitting the differentiation of six Braak stages (I through VI) (Braak and Braak, 1991).

Currently, $\mathrm{AD}$ neuropathology staging is predominantly based on Montine's ABC scoring system that combines $\mathrm{A} \beta$ deposit staging as described by Thal et al. (2002) (A score), Braak NFT staging (B score) (Braak and Braak, 1991), and finally neuritic plaque scoring (C score) (Montine et al., 2012). Neuritic plaques are characterized by a central core of $A \beta$ aggregates surrounded by a corona composed of degenerating neurons with dystrophic neurites and reactive astroglia and microglia.

\section{ARTERIAL STIFFNESS AS A RISK FACTOR OF ALZHEIMER'S DISEASE}

In recent years, there has been an increased interest in the potential contribution of vascular diseases in the $\mathrm{AD}$ pathogenesis because several vascular risk factors have been associated with this dementia syndrome, e.g., hypertension, metabolic syndrome, hypercholesterolemia, atherosclerosis, hyperlipidemia, certain forms of coronary disease, and more recently arterial stiffness. Among these vascular risk factors of $\mathrm{AD}$, hypertension appeared to be the strongest (Kennelly et al., 2009). Most clinical studies demonstrate that mid-life hypertension predisposes to the $\mathrm{AD}$ dementia syndrome in late life (Skoog et al., 1996; Kivipelto et al., 2001) as long-standing increments in blood pressure and blood pressure variations induce anatomical and functional alterations in the brain such as white matter changes, cerebral hypoperfusion due to atherosclerosis or the disruption of vasoregulatory functions (Kalaria, 2010; Lattanzi et al., 2014, 2015). Moreover, classspecific and dose-dependent antihypertensive therapies decrease the incidence of MCI and dementia (Takeda et al., 2009) and reduce the $\mathrm{AD}$ pathogenesis (Hoffman et al., 2009), making blood pressure an interesting therapeutic target. However, a global clinical study, including 18,017 hypertensive patients, concluded that merely $32 \%$ of patients treated with anti-hypertensives resulted in systolic blood pressure (SBP) control (Thoenes et al., 2010). Later, the REASON study (Protogerou et al., 2009) was able to explain this poor clinical outcome as they found a positive correlation between SBP and arterial stiffness, a strong independent predictor of CVD.

Already in the 17th century the concept of arterial stiffness was exemplified by the physician Thomas Sydenham (1624-1688) with his famous dictum "a man is as old as his arteries" This phrase is still valid because recent aging theories suggest that changes in vascular anatomy are an important determinant of an organism's fate (Learoyd and Taylor, 1966; Bailey, 2001; Lakatta and Lévy, 2003; Greenwald, 2007). With every heartbeat, nutrient-rich, oxygenated blood is ejected from the heart's ventricles into the arterial tree. The cyclic nature of the propagation and reflection of blood pulse waves not only define the mechanical force experienced by the vasculature but also the load imposed on each ventricle (Minor, 1982). This hemodynamic conduction behavior is maintained in mammals, where the mean pulse pressure at the base of the brain is remarkably similar between mice, dogs, humans, and even giraffes, whose hearts have to work a little harder to ensure optimal peripheral perfusion (Noordergraaf et al., 1979; Kass et al., 1988; Beyar et al., 1989). Overall, this cardiovascular phenomenon underscores an often ignored but profound characteristic of the cardiovascular circulation, namely that it is pulsatile (Kass et al., 1988).

In addition, the cardiovascular system ensures that the highpressure blood flow, generated by the intermittent pumping of the heart to the periphery, is captured to maintain a stable perfusion in vulnerable vascular beds with high and low resistance (Vlachopoulos et al., 2011). This dampening effect is accurately assessed in the Windkessel model as the ability of large arteries to immediately adapt to changing ejected blood volumes and to store the excess stroke volume during systole and to drain it during diastole (Chau et al., 1982; Safar et al., 2003; BenShlomo et al., 2014). Under physiological conditions, the stiffness of the arteries gradually increases from the heart to the periphery, which is partly due to the proximodistal narrowing of the arterial diameter. This stiffness gradient causes an impedance mismatch that induces partial wave reflections to reduce the transmission of pulsatile energy and to protect the microcirculation (London and Pannier, 2010). The concept of wave reflections is best understood by differentiating between velocity and pulse waves in the ascending aorta. Where the velocity wave is a single spurt from the heart that drops to zero at the incisura during the entire diastolic cycle, the pulse wave is reflected in two localized peaks, 
the first of which corresponds to the flow peak and the second to the summation of the reflection in that specific part of the body (London and Pannier, 2010; O'Rourke et al., 2014).

Whereas the Windkessel model is a non-propagative model of arterial stiffness, a more appropriate approach was introduced by Adriaan Isebree Moens (Dow, 1940) and Diederik Korteweg (Tijsseling and Anderson, 2012) with the Moens-Korteweg equation that describes both propagation and velocity. Given that pulse waves travel faster in stiffer arteries, the verification of pulse wave velocity (PWV) was suggested as a more reliable measurement of arterial stiffness (Safar and London, 1987). Recently, the Scandinavian physiologist Bjorn Folkow described how aging can distort the regulation of arterial function where progressive arterial stiffness causes increased arterial impedance and pulsatile pressure in the arterial tree (Folkow and Svanborg, 1993). As arterial tissue loses its elasticity with age, increased pulsatile strain damages the most vulnerable microcirculations (O'Rourke and Safar, 2005) such as the cerebrovasculature, leading to severe lesions and end-organ failure, e.g., cognitive decline and cerebral bleeding (O’Rourke and Hashimoto, 2007).

Under physiological conditions, arterial stiffness increases progressively from the heart to the periphery since the proximal aorta is more distensible than the distal tract. Together with the proximo-distal tapering of the arterial diameter, the stiffness gradient determines an impedance mismatch that induces reflection of the pulse wave. Partial wave reflections reduce the transmission of pulsatile energy to the periphery and, hence, protect the microcirculation. When proximal aortic stiffness increases and the physiological gradient is reduced or reverted, the pulse propagation cannot be adequately dampened, is transmitted to smaller arteries, and impinges on the microcirculation (Noordergraaf et al., 1979). In addition, less reflected waves return to the central aorta and increase systolic BP and pulse pressure by superimposing on the incident pulse waves (Tariot et al., 1995).

\section{LINK BETWEEN ARTERIAL STIFFNESS AND ALZHEIMER'S DISEASE}

In essence, arterial stiffness relates the pulsatility of the heart to the brain. Given its extensive microvasculature, the brain is not only a low-resistance but also a high-flow organ that is continuously exposed to cardiac pulsatile pressures and mechanical forces (O'Rourke and Safar, 2005). There is a consensus that heightened PWV is linked to a faster cognitive decline, changes in psychomotor speed and difficulties in semantic fluency and verbal learning despite discrepancies between studies in terms of study design (longitudinal vs. crosssectional), cognitive screening, target populations, and their heterogeneity (Rabkin, 2012; Hughes et al., 2015; van Sloten et al., 2015; Iulita et al., 2018). In this context, the ARICNS study concluded that higher arterial stiffness and pulsatility were associated with MCI and dementia mainly in Caucasian participants. Also the recent ASCEND study reported the influence of ethnicity on peripheral vascular health in a healthy middle-aged cohort at risk for AD (Meyer et al., 2017). The study concluded that African Americans had worse peripheral vascular health and cognition compared to non-Hispanic White Americans (Kumar et al., 2020). Furthermore, physical excercise has been reported as a strong predictor of both arterial stiffness and cognition in the elderly. In general, a greater exercise engagement predicted better cognition in those with lower fitness, while arterial stiffness measurements were on their turn indicative of an individual's physical fitness and cognitive status (Asamoah et al., 2013; Nascimento et al., 2019; Pereira et al., 2019; Kennedy et al., 2020; Mason et al., 2020). Additionally, genetic predisposition linked to the APOE4 gene was recently proposed to act synergistically with arterial stiffness to predict cognitive impairment in non-demented elderly (Rodrigue et al., 2013; Cambronero et al., 2018; Rivera-Rivera et al., 2020; Smirnov et al., 2020; Figure 1).

Evaluation of altered brain structure due to arterial stiffness has been extensively investigated through cross-sectional and longitudinal epidemiological studies using MRI images and/or CT scans. One of the most specific recurring findings was the correlation between increased PWV measurements and a higher incidence of greater white matter hyperintensities and white matter dysintegrity (Henskens et al., 2008a,b; Coutinho et al., 2011; Mitchell et al., 2011; Poels et al., 2012; Tsao et al., 2013; Pase et al., 2016; Arai et al., 2018; Suri et al., 2020). Other brain screening programs also reported that PWV values were related to brain atrophy (Tsao et al., 2013; Pase et al., 2016). On a cerebrovascular level, heightened PWV values correlated to cerebral infarcts (Matsumoto et al., 2007; Henskens et al., 2008b; Tsao et al., 2013), microbleeds (Henskens et al., 2008a,b) and the presence of cerebral hypoperfusion (Muller et al., 2007; Watson et al., 2011; Jefferson et al., 2018; Suri et al., 2020). Other research groups applied A $\beta$-PET imaging in combination with PWV measurements in large human cohorts in order to investigate the convergence between arterial stiffness and $\mathrm{AD}$. Overall, arterial stiffness was independently associated with a greater brain $\mathrm{A} \beta$ burden and the presence of CAA (Hughes et al., 2013, 2014, 2018; Moon et al., 2019; Pasha et al., 2020). Taken together, imaging-based cross-sectional and longitudinal studies in both symptomatic and asymptomatic subjects emphasize the association between increased PWV measures and cerebral damage in terms of cerebrovascular damage, neurodegeneration, an increased $\mathrm{A} \beta$ burden and CAA (Figure 1).

Although overwhelming evidence highlights the association between arterial stiffness and $\mathrm{AD}$ in (a)symptomatic human subjects, these studies are limited by correlative evidence. Animal models of large artery stiffness on the other hand, allow researchers to better investigate the causative mechanisms linking both diseases, though each with their own strengths and limitations. Examples include murine models with a partial or complete eNOS deletion (Austin et al., 2013; Tan et al., 2015; Li et al., 2018; Austin and Katusic, 2020), displaying heterozygous fibrillin 1 (Leloup et al., 2018) and elastin (Hughes et al., 2014; Said et al., 2018), carotid artery calcification (Muhire et al., 2019; Neuner et al., 2019), and transverse aortic constriction (Demer and Tintut, 2008; Steppan et al., 2012; Cooper and Mitchell, 2016). Common symptoms in these rodents comprise an increased (neuro)inflammatory state, changes in cerebrovascular 


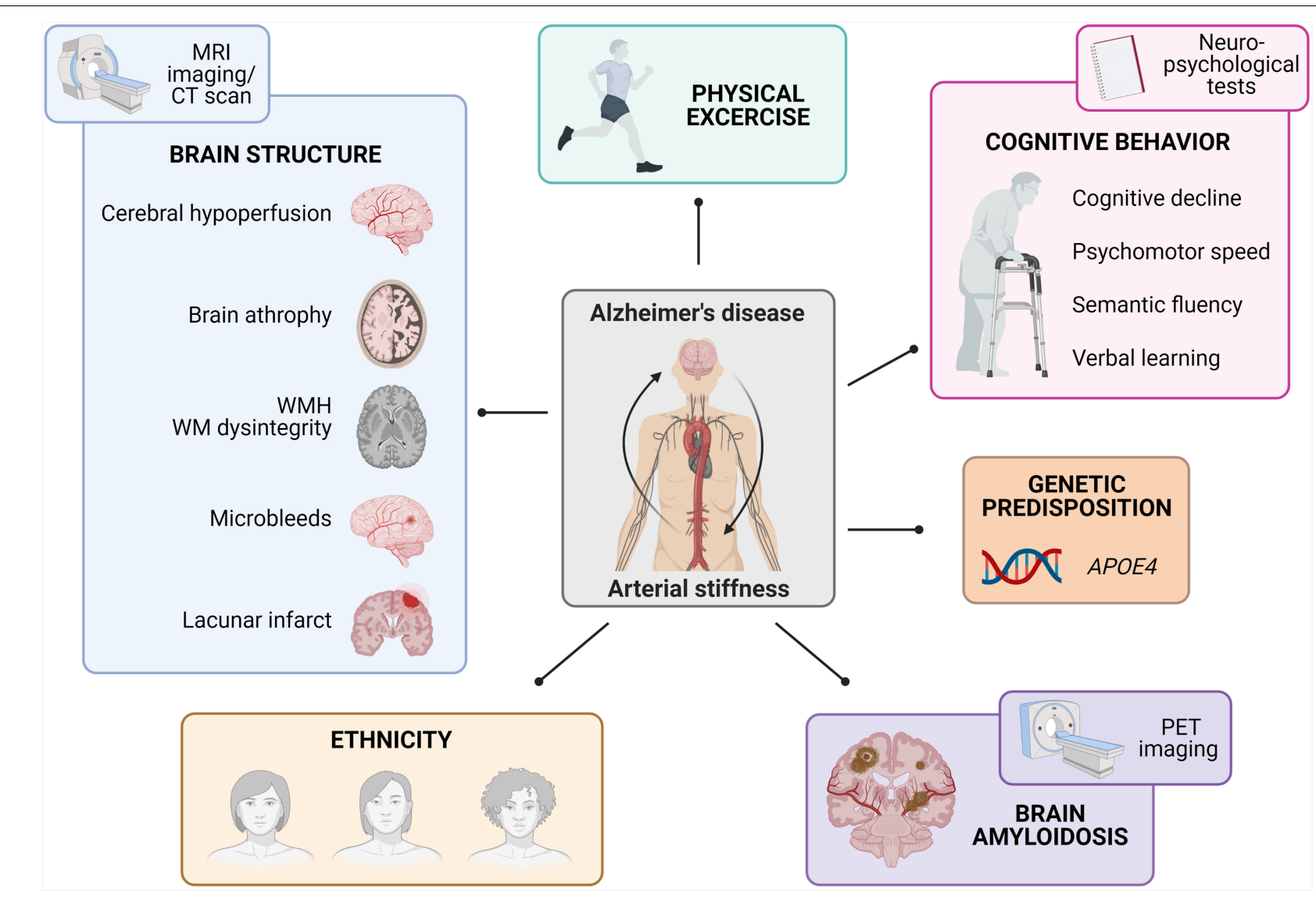

FIGURE 1 | Summary of epidemiological findings linking arterial stiffness to Alzheimer's disease. The observed links between arterial stiffness and Alzheimer's disease comprise brain structure changes (as studied via MRI-based imaging techniques), physical fitness, cognitive behavior (as studied with neuropsychological tests), APOE4 genetic predisposition, brain amyloidosis (as studied via A $\beta$-PET imaging), and differences in ethnicity (MRI, magnetic resonance imaging; MWH, white-matter-hyperintensities; WM, white matter; PET, positron emission tomography).

structure and/or blood flow and a dementia phenotype alongside altered arterial stiffening and blood pressure features (Figure 2). Although proof-of-concept evidence has been established, knowledge gaps of the related causative mechanisms of arterial stiffness on $\mathrm{AD}$ remain. Identifying commonalities between these available models and their continuous characterization is therefore crucial. An additional hampering factor is the fact that rodents do not naturally accumulate $A \beta$. Therefore, the combination of large artery stiffness and transgenic $\mathrm{AD}$ models is needed. From a future perspective, more attention should be paid to possible effects of gender differences and influences of genetic background (Qosa and Kaddoumi, 2016; Neuner et al., 2019). Once the mechanisms underlying the convergence between arterial stiffness and $\mathrm{AD}$ are solidified, more precise interventions can be developed to delay the onset and/or progression of the $\mathrm{AD}$ pathogenesis.

\section{CAUSES OF ARTERIAL STIFFNESS}

Epidemiological research clearly indicates that chronological aging is the main determinant of arterial stiffness (Ishida et al., 2018; Namba et al., 2019). Aging is a ubiquitous complex phenomenon caused by a subtle blend of (epi)genetic alterations and individualized lifestyle factors (LaRocca et al., 2017; Morris et al., 2019; Wahl et al., 2019; Zhang et al., 2020b). Prolonged and cumulative exposure to these stimuli dysregulates and hyperactivates one of the body's major stress system, being the hypothalamus-pituitary-adrenal (HPA)-axis, causing a generalized stress response by the release of stress hormones such as cortisol (Starr et al., 2019). A dysregulated HPA-axis negatively impacts overall health and activates the body's immunoinflammatory system (Tapp et al., 2019; Ahmad et al., 2020). Rather than being considered as an individual pathophysiology that comprises a simple "cause or consequence" connection, we propose that stress-driven, age-related perturbation of a chronic low-grade pro-inflammatory status, coined as inflammaging, (Franceschi et al., 2007; Chadwick et al., 2012) underlies arterial stiffness. Non-resolved inflammaging determines lifespan and the speed of aging, and is therefore highly associated with aging-related diseases including AD (Giunta et al., 2008), as well as with arterial stiffness (Fukami et al., 2020), insulin resistance (IR) (Itariu and Stulnig, 2014), nitro-oxidative inflammation (Miquel, 2009), and an impaired autophagic 


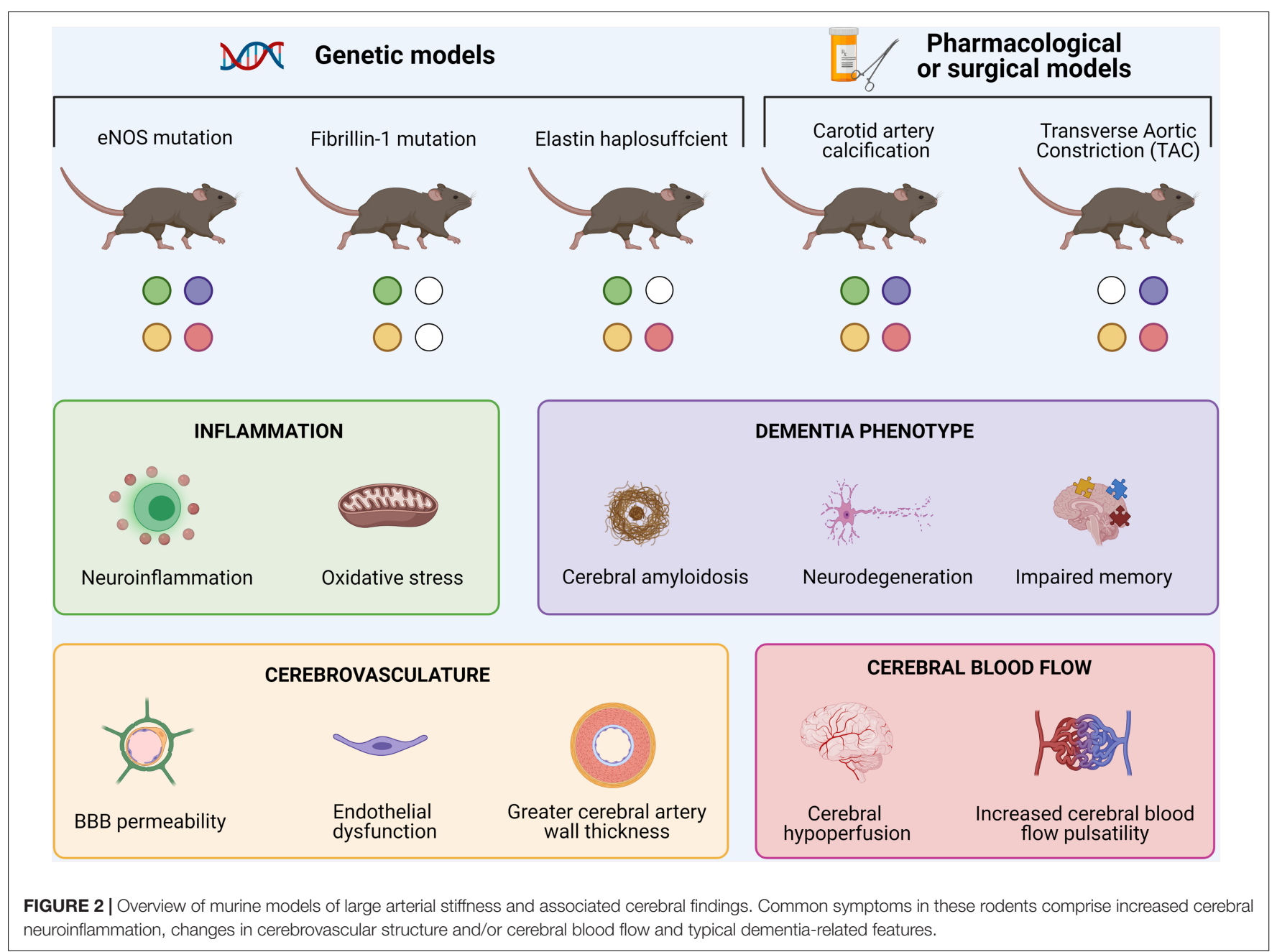

machinery (Salminen et al., 2012). The other way around, the deleterious effect of elevated glucocorticoid levels has been demonstrated in inflammaging-associated diseases such as AD (Khalsa, 2015; Justice, 2018), arterial stiffness (Vlachopoulos et al., 2009), acute inflammation (Guerrero, 2017), impaired autophagy (Ma et al., 2019), nitro-oxidative stress (Bernatova et al., 2018), and IR (Burke et al., 2017). Aside from the overwhelming linkage between arterial stiffness and $\mathrm{AD}$, recent evidence implies that arterial stiffness in itself is also associated with the aforementioned inflammaging pathologies such as IR (Cozma et al., 2018; Khoshdel and Eshtiaghi, 2019), nitrooxidative stress (Bailey et al., 2013; Mozos and Luca, 2017), inflammation (Jain et al., 2014; Peyster et al., 2017) and reduced autophagy (Chen and Sun, 2019; McCarthy et al., 2019; Figure 3). In the following sections, we discuss stress-driven inflammaging as a mechanistic convergence between arterial stiffness and AD.

\section{Tissue-Specific Inflammation}

The human body is constantly exposed to a multitude of noxious biological, chemical, and physical stimuli. Throughout evolution, the human body has developed mechanisms to recognize and to respond to those stimuli in order to maintain general health. Inflammation represents one of the body's complex biological responses to those threats (Medzhitov, 2008). The concept of inflammation is generally divided into acute and chronic inflammation although both concepts overlap. Acute inflammation embodies the migration of immune cells to the site of injury facilitated by soluble immune-mediators (e.g., chemokines, acute-phase proteins, and cytokines). Depending on the severity of the injury, acute inflammation might not be sufficient to resolve the damage. Consequently, the prolonged and persistent exposure to stimuli evolves to a chronic inflammatory state in which tissue damage and fibrosis occurs (Germolec et al., 2018).

\section{Neuroinflammation}

For many decades, the brain was considered a fully immuneprivileged organ, but this concept has faded and is replaced with a relative model of neuroinflammation involving a sophisticated immune response (Louveau et al., 2015). Despite a diversity in clinical symptoms, neurodegenerative disorders share common pathogenic cascades. Often the basis is the misfolding of proteins that aggregate in a disease-specific spatiotemporal pattern, which is associated with significant neuroinflammation contributing 


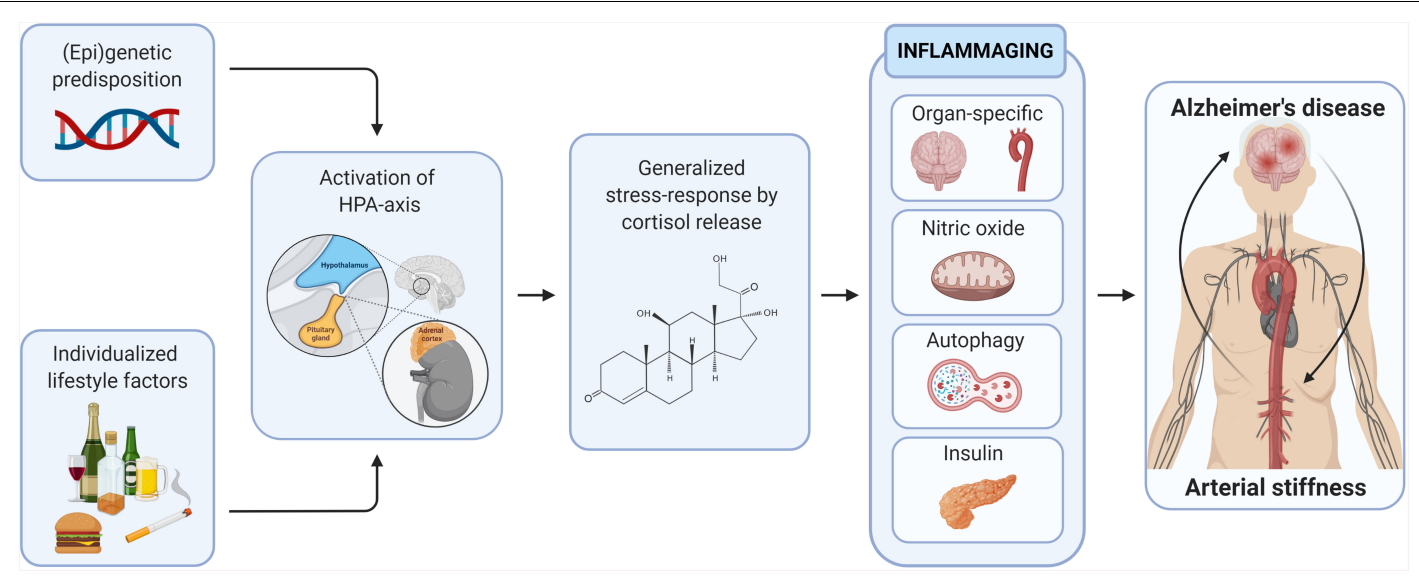

FIGURE 3 | Inflammaging as the mechanistic convergence between arterial stiffness and Alzheimer's disease. The long-term causal effect of (epi)genetic predisposition and individualized lifestyle factors and consequent generalized stress-response on several inflammaging-related drives the mechanistic convergence between arterial stiffness and Alzheimer's disease.

to disease onset and progression. This pathogenic pathway also appears pivotal in AD. Firstly, a strong link was established between $\mathrm{AD}$ and the innate immune response with microglial cells as its main players in the brain. Since microglia primarily locate in the vicinity of amyloid plaques (neuritic plaques) (Serrano-Pozo et al., 2011) and interact with A $\beta$ and extracellular NFTs (Cras et al., 1991; El Khoury et al., 1998), AD-associated neuroinflammation was originally viewed as a passive response to these protein depositions. However, more recent insights grant an active contribution of inflammatory processes to $\mathrm{AD}$ pathogenesis, with the implication of both the innate and adaptive immune response, rendering neuroinflammation another AD hallmark (Heneka et al., 2015; Webers et al., 2020).

Microglia represent the main sensor of the brain's innate immune system. Resting microglia display a ramified morphology and weak antigen presenting activity. Upon activation by tissue damage or pathogens, their morphology changes to an amoeboid-like shape allowing them to navigate through neuronal tissue. Local regeneration after neuronal damage is based on increased production of anti-inflammatory cytokines and neurotrophic factors, and the facilitation of phagocytosis of cell debris, as such promoting neuronal repair and survival (Kreutzberg, 1996; Nimmerjahn et al., 2005). In a healthy aging brain, microglia evolve toward a more inflammatory phenotype, as such contributing to the inflammaging phenomenon. This microglia priming or sensitization lies at the basis of a vicious cycle of exaggerated pro-inflammatory responsiveness significantly contributing to neurodegeneration in the AD brain (Norden and Godbout, 2013; Franceschi and Campisi, 2014).

Besides participating in several critical physiological functions, such as blood-brain barrier (BBB) integrity and the regulation of axonal outgrowth and myelination, astrocytes are important cellular regulators of the innate immune system. Reactive astrogliosis has also been demonstrated in the $\mathrm{AD}$ brain, especially in the vicinity of amyloid plaques (Medeiros and LaFerla, 2013). Astrocytes play a critical role in clearing
$\mathrm{A} \beta$ plaques by the process of phagocytosis and secretion of $\mathrm{A} \beta$-degrading proteases. Analogously to microglia, astrocytes release cytokines, interleukins, nitric oxide (NO), and other potentially cytotoxic molecules upon exposure to $\mathrm{A} \beta$ thereby exacerbating neuroinflammatory processes (Jensen et al., 2013; Skaper et al., 2018). Reciprocal interactions between microglia and astrocytes play an essential role in both healthy brain and neurodegenerative processes (Bouvier and Murai, 2015). Although both glial cell types appear to contribute to neuroinflammation in $\mathrm{AD}$, the timing and mechanism of their involvement may differ substantially. The cellular characteristics of microglia support a stronger role in the initial stages of the neuroinflammatory cascade, while expression and release of tumor necrosis factor alpha (TNF- $\alpha$ ) from those early recruited microglia could initiate a wave of signals complemented by the co-release of, for example, reactive oxygen species (ROS) to initiate reactive pathways in proximate astrocytes (Kreutzberg, 1996; Bouvier and Murai, 2015).

The involvement of the adaptive immune system in neurodegenerative disorders such as $\mathrm{AD}$ can also be presumed. Peripheral $\mathrm{T}$ lymphocyte activation and infiltration into cerebrospinal fluid and brain could be an important contributing factor to $\mathrm{AD}$ pathology. Infiltrated $\mathrm{CD} 3+\mathrm{T}$ cells, mostly of the CD8+ subtype, were described in post-mortem human brain parenchyma (Itagaki et al., 1988; Rogers et al., 1988; Togo et al., 2002). In contrast to gliosis, the presence of CD3+ $\mathrm{T}$ cells often correlates stronger with tau- than with amyloid neuropathology (Merlini et al., 2018). Additionally, T-cell subsets in cerebrospinal fluid and peripheral blood show disease-related alterations. Decreased regulatory $\mathrm{T}$ cell, increased Th17 and increased $\mathrm{CD} 8+\mathrm{T}$ cell levels were measured in blood of AD patients (Oberstein et al., 2018; Ciccocioppo et al., 2019; Burgaletto et al., 2020; Gate et al., 2020), while clonally expanded antigen-specific CD8 $+\mathrm{T}$ cells were present in cerebrospinal fluid of AD individuals (Gate et al., 2020), indicative of T cell trafficking into the central nervous system. In a similar fashion to the innate immune response, the adaptive immune system 
can develop a "friend or foe" relationship in AD. Various animal model-based studies have illustrated that controlled regulatory $\mathrm{T}$ cell depletion may be neuroprotective and mitigate $\mathrm{AD}$ progression via the suppression of harmful $\mathrm{T}$ cell subsets and even the modulation of the microglial response to amyloid- $\beta$ deposition (Baruch et al., 2015; Dansokho et al., 2016; Baek et al., 2018; Mayne et al., 2020).

\section{Vascular Inflammation}

One key mechanism of arterial stiffness is aging of the arterial wall which is characterized by a chronic pro-inflammatory state coined "inflammaging." Vascular inflammaging entails the production of proinflammatory stressors due to the failure of key molecular signaling cascades such as endothelin, renin/angiotensin II and the mineralocorticoid receptor signaling pathway (Lakatta, 2013; Wang et al., 2014). Consequently, the expression of pro-inflammatory transcription factors is facilitated (Wang et al., 2014). Vascular inflammation leads to structural remodeling of the arterial wall including vascular smooth muscle cell (VSMC) senescence and proliferation, vascular fibrosis, elastin breakdown, extracellular matrix (ECM) formation, and vascular calcification (Figure 4).

VSMCs are able to undergo several phenotypic switches causing proliferative, senescent and stiffened VSMCs to coexist in the aging arterial wall. Senescent VSMCs contribute to a pro-inflammatory state by the secretion of pro-inflammatory cytokines (IL-1, IL-6, and IL-17), monocyte chemoattractant protein-1 (MCP-1) and TNF- $\alpha$ (Csiszar et al., 2012; Accardi et al., 2016). It is hypothesized that this age-associated arterial secretory phenotype stimulates neighboring VSMCs to undergo a phenotypic switch in a juxtacrine fashion (Khan et al., 2010). Aged VSMCs in the arterial wall have an enhanced proliferation capacity marked by a greater percentage of cells in the $S$ and $\mathrm{G} 2 / \mathrm{M}$ phases and less cells in the G0/G1 phase. In vivo and in vitro research demonstrated the elevated expression of milk fat globule-EGF factor 8 protein (MFG-E8) and downstream integrin/ERK1/2 signaling to control VSMC proliferation and the cell cycle (Wang et al., 2012; Chiang et al., 2019). Moreover, old VSMCs exhibit an exaggerated migration/invasion capacity from the arterial media to the intima leading to age-associated diffuse intimal thickening (Spinetti et al., 2004; Fu et al., 2009; Wang et al., 2012). In vitro findings concluded the pivotal relay of MFGE8 in VSMC migration and invasion (Fu et al., 2009). In addition, specific cleavage of the MFG-E8 protein leads to the formation of the amyloid protein, medin. This protein is deposited in the aortic media of the majority of European-Americans aged 50 and older (Wang et al., 2013; Migrino et al., 2017; Younger et al., 2020). Thus, the amyloidogenic MFG-E8/medin complex might accompany arterial stiffness with advanced age. Indeed, a positive correlation between PWV and serum MFG-E8 serum levels has been established in the elderly (Cheng et al., 2012).

A key feature of arterial aging is elastin fragmentation in the lamellae of the arterial medial layer. With time a greater strain is transferred to the less compliant collagen fibers in the ECM. Although long considered a passive phenomenon, elastin fragmentation can be acutely initiated by proteolytic elastase activity during instantaneous inflammatory responses. Certain

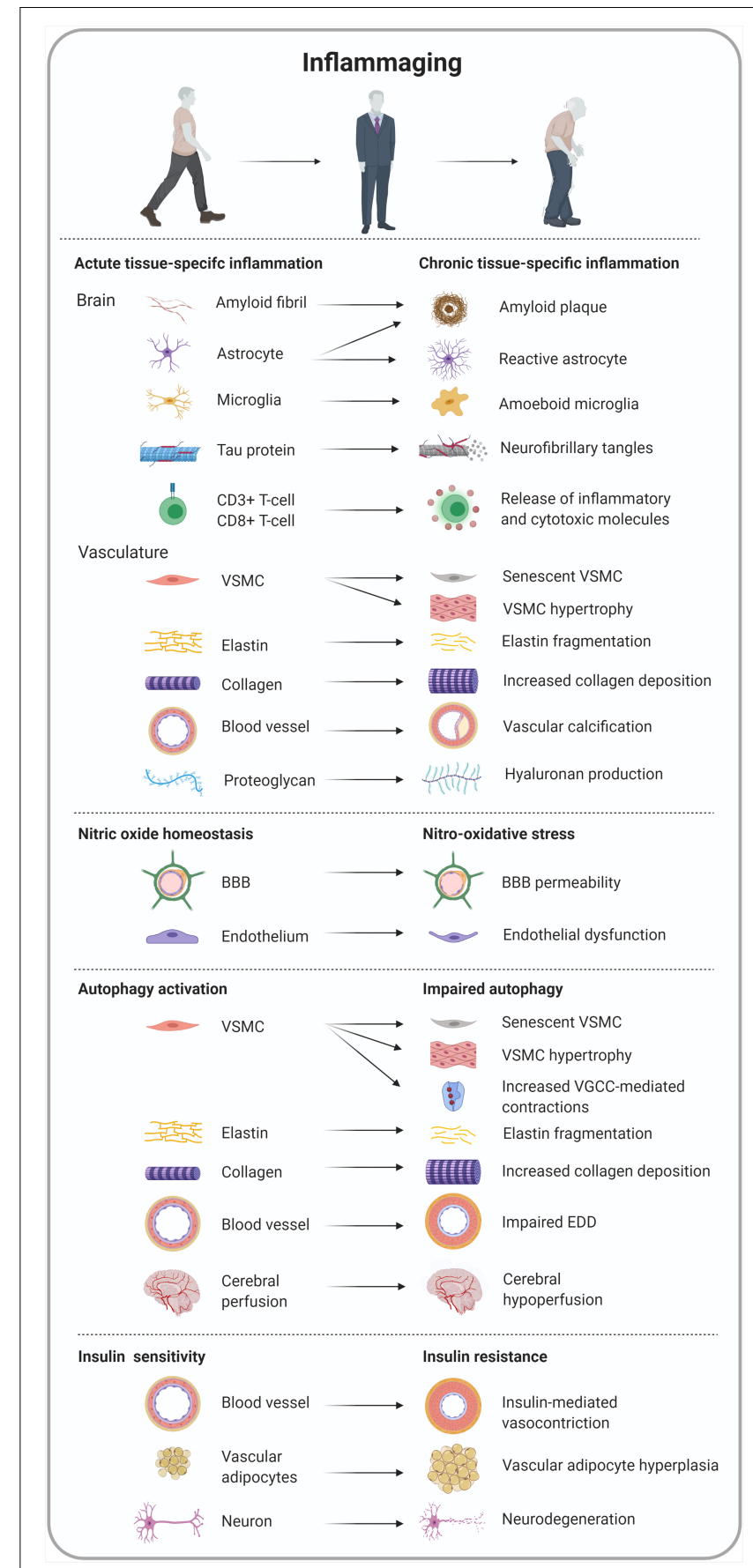

FIGURE 4 | Overview of tissue-specific cell morphology and functionality in inflammaging-related conditions converging arterial stiffness and Alzheimer's disease.

matrix metalloproteinases (MMPs) are constitutively expressed by endothelial cells (ECs) and VSMCs upon inflammation, though these are counterbalanced by tissue inhibitor of metalloproteinases 2 (TIMP-2) in normal conditions (Park and Lakatta, 2012). Under the influence of inflammatory cytokines and the increased activity of cell adhesion molecules, 
macrophages, and neutrophils produce MMPs (including MMP1, MMP-2, MMP-7, and MMP-9) (Galis and Khatri, 2002). These MMPs deteriorate the elastin-collagen crosslinking due to the degradation of basement membranes and their collagenolytic activity (Park and Lakatta, 2012), thereby stimulating uncoiled collagen, and thus arterial stiffening (Zieman et al., 2005). On a clinical level, the expression of relevant MMPs has been demonstrated to correlate to increased PWV levels (Wykretowicz et al., 2005; Yasmin et al., 2005; Vlachopoulos et al., 2007). A salient feature of ECM formation is enhanced collagen deposition. The complex meshwork of the ECM (collagen I, II, and III) is produced and maintained by VSMCs. The production of collagen molecules by VSMCs is governed by increased MMP-2 activated TGF $\beta 1$ signaling eventually leading to vascular fibrosis (Wang et al., 2006; Jiang et al., 2012). Furthermore, stiffer arteries comprise the ECM to resist compression. ECM inflammation causes an enhanced synthesis of glycosaminoglycans such as hyaluronan and altered proteoglycan structures. Hyaluronan forms a gel within the ECM by trapping water causing an impaired compression ability of the arterial wall (Maki-Petaja et al., 2012; Lorentzen et al., 2016; Maki-Petaja et al., 2016).

Similar to osteoblasts, VSMCs are able to undergo osteogenic differentiation when exposed to increased intracellular concentrations of calcium and/or inorganic phosphate (Neutel et al., 2020). Overexpression of calpain-1 reduces the calcification inhibitors such as osteopontin and osteonectin (Jiang et al., 2012; Tang et al., 2015). In addition, increased tissue transglutaminase (TG2) downregulates calcification-inhibitory genes (e.g., Opn) and upregulates calcification-promoting genes (e.g., Runx2) underlining its activation as an important molecular event in vascular calcification (Konoplyannikov and Nurminskaya, 2014; Chen W. R. et al., 2019).

\section{Link Between Vascular Inflammation and Neuroinflammation}

Aside the well-studied local inflammatory processes in arterial stiffness and $\mathrm{AD}$, the effect of systemic inflammation on both pathologies has been put forward in recent years. A growing body of evidence suggests that systemic inflammation is associated or precedes arterial stiffness (Mahmud and Feely, 2005; Durham et al., 2018). Recently, it was reported that patients with chronic inflammatory diseases (e.g., rheumatoid arthritis, systemic sclerosis, systemic lupus erythematosus, and inflammatory bowel disease) present higher PWV values as compared to control subjects (Dregan, 2018; Vargas-Hitos et al., 2018). Moreover, at the level of the brain, systemic inflammation, marked by elevated circulatory proinflammatory cytokines, can shape a cerebral inflammatory milieu promoting neurodegeneration and AD (Paouri and Georgopoulos, 2019; Walker et al., 2019). Indeed, systemic inflammation has been demonstrated to induce cognitive decline and behavioral changes (Kahn et al., 2012; Anderson et al., 2015; Riazi et al., 2015; Sankowski et al., 2015). These findings have raised the question whether systemic inflammation plays a compensatory, mechanistic, or perhaps merely an associative role in the convergence between arterial stiffness and $\mathrm{AD}$.
Accumulating experimental and clinical evidence suggests that $A \beta$-peptides, $A \beta 1-40$ in particular, exert proinflammatory properties in the peripheral and cerebral vasculature (NoguchiShinohara et al., 2017; Stamatelopoulos et al., 2015, 2018; Visconte et al., 2018), making this an interesting biomarker. Several interventions using statins, angiotensin-converting enzyme inhibitors, angiotensin receptor blockers, angiotensin receptor/neprilysin inhibitors, $\beta$-blockers, diuretic agents, calcium-channel blockers, and hemodialysis showed the feasibility to manipulate the APP/A $\beta$ turnover, aggregation of $\mathrm{A} \beta 1-40$ peptides or blockage of its inflammatory properties (Stakos et al., 2020). Furthermore, the age-associated amyloidogenic protein medin has been associated with vascular and cerebrovascular inflammation in recent years as it provokes endothelial dysfunction (Migrino et al., 2017; Degenhardt et al., 2020; Migrino et al., 2020; Younger et al., 2020). In this way, medin could also be considered an important inflammatory biomarker in the early-stages of the arterial stiffness and/or AD pathology. Recently it has been suggested that inflammaging increases the production of methylglyoxal, a dicarbonyl derivative of glucose. Increased levels of methylglyoxal may exacerbate stiffness and cognitive decline mainly in diabetic subjects (Dhananjayan et al., 2017).

Elucidating the underlying mechanisms of action of the aforementioned biomarker candidates might govern the crosstalk between systemic and local vascular and cerebral inflammation. On the long run, this understanding may provide the ground for new anti-inflammatory therapeutic approaches that successfully target arterial stiffness and/or AD.

\section{Nitro-Oxidative Stress}

Although being the smallest gaseous signaling molecule, NO is responsible for maintaining homeostasis in a myriad of tissues and molecular pathways (Balaiya and Chalam, 2014) and embodies a key role in the pathogenesis of inflammation, though it is a double-edged sword (Sharma et al., 2007). In normal physiological conditions, NO exerts an anti-inflammatory function (Sarkate et al., 2017; Sherikar et al., 2019; Zhang et al., 2020a) while NO is also considered a pro-inflammatory mediator in pathological conditions, such as arterial stiffness (Sindler et al., 2011; Isabelle et al., 2012; Aroor et al., 2018; Chiba et al., 2019) and AD (Cifuentes et al., 2017; Tang et al., 2019; Austin and Katusic, 2020; Dubey et al., 2020; Stefano et al., 2020) mainly due to its contribution in nitro-oxidative stress (Pérez-Torres et al., 2020; Figure 4).

Vascular endothelial NO production is considered the most important vasodilator mechanism for the preservation of proper vasomotor function. The entire vascular system, from the heart to the smallest capillaries, is covered with an intimal endothelial monolayer which forms a barrier between circulating blood and surrounding tissues. By the release of $\mathrm{NO}$, the vascular endothelium modulates basal and dynamic blood vessel diameter changes (Bauer and Sotníková, 2010). Indeed, the presence of arterial stiffness has previously been shown in rodent models of endothelial dysfunction by the inhibition of endothelial nitric oxide synthase (eNOS) with $\mathrm{N}(\mathrm{G})$-Nitro-L-Arginine Methyl Ester (L-NAME) or by a genetic eNOS knock-out which causes 
hypertension and increased carotid-femoral PWV (Isabelle et al., 2012; Leloup et al., 2014). A diet-induced intervention in old mice with sodium-nitrite, on the other hand, led to de-stiffening of large arteries and normalized PWV values (Sindler et al., 2011).

The generation of endothelial NO and/or its bioavailability can be diminished by the increased generation of upstream oxidative stress. On itself, oxidative stress contributes to endothelial dysfunction by the rapid oxidative inactivation of NO through the excessive production of superoxide. As a result, eNOS activity uncouples and NO bioavailability decreases, creating a nitroso-redox imbalance and overall nitro-oxidative stress which precedes numerous vascular pathologies (Taverne et al., 2012; Sena et al., 2013). Excessive oxidative stress and consequent eNOS uncoupling have been demonstrated in mouse models (Xia et al., 2010; Herranz et al., 2012; Varadharaj et al., 2012; Yin et al., 2017) and patients with atherosclerosis (Varadharaj et al., 2012; Ismaeel et al., 2018) as well as in animal models (Adlam et al., 2007; Toral et al., 2018; Cheng et al., 2020; Dong et al., 2020) and patients with hypertension (Cengiz et al., 2015). Reactive oxygen species (ROS, e.g., superoxide) are formed, among other things, by multi-subunit NADPH oxidase (NOX) complexes from molecular oxygen using NADPH as electron donor. For many years, NOX expression was thought to occur only in infiltrating monocytes/macrophages and phagocytes. However, NOX expression has also been recently observed in vascular wall components (Panday et al., 2015). As such, NOX2 is considered the most prominent vascular NOX isoform as it is also expressed in VSMCs, adventitial fibroblasts, ECs, and perivascular adipocytes (Briones et al., 2011; Konior et al., 2014; Chen J. et al., 2017; Ling et al., 2018). A recent study demonstrated that the vascular infiltration of Nox $2+$ myeloid cells causes vascular inflammation resulting into endothelial dysfunction in a heart failure murine model ensuing myocardial infarction (Molitor et al., 2021). Furthermore, inhibition of the MRs/Nox2 redox signaling pathway via the downregulation of acid sphingomyelinase was shown to positively improve vascular adventitial remodeling in primary rat fibroblasts treated with angiotensin II ( $\mathrm{Li}$ et al., 2019). In the cerebrovasculature of the AD brain, ROS are primarily generated via NOX2 in the diseaseassociated microglia. The enhanced activation of NOX2 in these microglia is associated with increased neuroinflammation and amyloid plaque deposition (Simpson and Oliver, 2020).

In this context, the link between arterial stiffness and $\mathrm{AD}$ has been mainly attributed to a loss of BBB integrity (Taheri et al., 2011; Wardlaw et al., 2013). Because the brain has no fuel reservoir, the brain draws energy from blood supplied by the cerebrovasculature through the BBB (Iadecola, 2017). The BBB serves as the first line of defense of the brain's unique microenvironment against the systemic blood circulation (Sweeney et al., 2019). It has been proposed that downregulation of cerebrovascular eNOS expression predisposes certain brain areas to lose their BBB integrity (Soares et al., 2015; Al-Zaiti et al., 2018; Munji et al., 2019; Zhang et al., 2019; Bernstein et al., 2020). Intact endothelium and consequent preserved NO production in the cerebrovasculature is thus important to prevent stroke, cerebrovascular disease and neurodegeneration (Tabatabaei and Girouard, 2014; Khan et al., 2019; Haselden et al., 2020). A study from a metabolic point of view concluded that Type
1 diabetes driven eNOS-deficiency increases BBB permeability (Mayhan et al., 2015). Another study in a rat epilepsy model showed that increased cerebral eNOS expression led to BBB breakdown through provocation of a status epilepticus. This observation was further strengthened by the administration of an eNOS inhibitor (Ko et al., 2015). The opposite interpretation was derived from a study investigating the eNOS gene deletion in the $\mathrm{BBB}$ of a thiamine-deficient murine model. Here, knocking out eNOS restored BBB permeability, suggesting that eNOSderived NO is an important factor in the cerebrovasculature of this pathology (Beauchesne et al., 2009). More specifically, an accumulative body of evidence speculates that the main culprit behind cerebrovascular dysfunction, as seen in $\mathrm{AD}$, is oxidative stress and ROS production. It is known that ROS formation in the presence of $\mathrm{A} \beta$ peptides reduces NO bioavailability in the cerebrovasculature (Miller et al., 2010; Austin and Katusic, 2020). A rise of ROS seems to be mainly caused by $A \beta$-driven NOX2 activation eventually triggering neuroinflammation (Han et al., 2015; Wyssenbach et al., 2016; Hwang and Kim, 2018). This neuroinflammatory response involves the altered expression of tight-junctions in cerebrovascular ECs leading to a loss of BBB integrity and CAA (Carrano et al., 2011, 2012).

In addition to its role in the $\mathrm{BBB}$, the importance of endothelial $\mathrm{NO}$ in the amyloidogenic processing of APP has been reported in the human and rodent cerebrovasculature (Austin et al., 2013; Austin and Katusic, 2016, 2020). A study in aged eNOS heterozygous mice demonstrated increased $A \beta$ accumulation in cerebrovascular tissue without any increased amyloidogenic depositions in the brain (Austin and Katusic, 2020), likely due to only a partial loss of eNOS. However, a similar study in more severely aged eNOS knock-out mice evidenced increased APP expression and amyloidogenic processing in both vascular and brain tissue alongside microglial activation and impaired memory performance (Austin et al., 2013). Given its antiplatelet and vasorelaxant effects, reduced NO bioavailability, because of NOX2 induced oxidative stress (Malkov et al., 2020), likely promotes platelet hyperactivation and coagulation that worsens the pro-thromboembolic phenotype observed in the cerebral microvasculature of AD patients (Veitinger et al., 2014; Canobbio et al., 2015; Bose et al., 2019). Furthermore, it is known that platelets are a systemic source of APP processing and thus the generation of A $\beta$ peptides (Chen M. et al., 1995; Foidl et al., 2020). Altogether, a decreased NO bioavailability in the cerebrovasculature not only drives cerebrovascular thrombosis, it also contributes to CAA which are both risk factors of stroke, cerebral hemorrhages and overall neuroinflammation.

To date, the exact role of nitro-oxidative stress in the linkage between arterial stiffness and $\mathrm{AD}$ is still under debate and needs further exploration in order to reach a more conclusive interpretation.

\section{Impaired Autophagy}

Macroautophagy, hereafter referred to as autophagy, was described 50 years ago as a cellular homeostatic process that repurposes molecules for cell survival (De Duve and Wattiaux, 1966). However, in the last decades the role of autophagy has also been linked to physiological processes such as inflammation by its functionality in virtually all cell 
types and more particularly in immune cells (Figure 4). These observations not only underscored the importance of autophagy, but also sparked enthusiasm for targeting this cellular process in inflammatory diseases (Matsuzawa-Ishimoto et al., 2018). Autophagy maintains intracellular homeostasis by degrading unnecessary or dysfunctional cellular components in lysosomes. The process starts with the formation of double-membrane vacuoles or autophagosomes that engulf small portions of the cytosol such as protein aggregates, lipid droplets, and complete organelles. By fusing with a lysosome, the autophagosomes eventually turn into autolysosomes. During this final step, the cytoplasmic content of the autophagosomes will be degraded by lysosomal hydrolases. Growing in vitro and preclinical evidence indicates that basal autophagy in ECs and VSMCs is an essential process, mediating proper vascular function (De Meyer et al., 2015). Indeed, autophagy in vascular physiology plays a crucial role in lipid metabolism (Khawar et al., 2019), vascular reactivity (Michiels et al., 2015; De Munck et al., 2020b), homeostasis (Ouseph et al., 2015) and the maintenance of blood glucose and amino acid levels (Ezaki et al., 2011). Interestingly, autophagy is activated by stress-related signals, such as nutrient deprivation, oxidative injury, and endoplasmic reticulum stress. In this way, autophagy supports cell survival in unfavorable conditions. It also represents a reparative and lifesustaining process as autophagy induction extends life span in various species. However, aging is associated with a decline in autophagy in different tissues, including the arterial tree, due to a decreased expression of autophagy-related proteins (LaRocca et al., 2012), which in turn promotes arterial disease, such as arterial stiffness and accelerated atherogenesis. Indeed, ex vivo experiments with aortic segments isolated from mice with a VSMC autophagy defect (deletion of the essential autophagy gene Atg7) revealed attenuated compliance and higher arterial stiffness (De Munck et al., 2020c). Because the differences in compliance and stiffness are more pronounced when VSMCs are completely relaxed by the addition of exogenous NO, passive aortic wall remodeling, as shown by a decrease in elastin and an increase in collagen content, rather than differences in VSMC tone, is responsible for these effects (De Munck et al., 2020c). Passive remodeling of the aortic wall is supported by histological data showing an increase in medial wall thickness and elevated elastin fragmentation. Defective autophagy in VSMCs also leads to profound changes in $\mathrm{Ca}^{2+}$ homeostasis, resulting in higher basal $\mathrm{Ca}^{2+}$ stores, and larger voltage-gated calcium channel-mediated contractions (Michiels et al., 2015; De Munck et al., 2020b). In addition, autophagy deficiency in VSMCs triggers cellular hypertrophy and increases stress-induced premature cellular senescence (Grootaert et al., 2015). Because senescent cells lose their replication potential and have a pro-inflammatory secretory phenotype (i.e., Senescence Associated Secretory Phenotype or SASP), this condition has been linked to a number of agerelated diseases, including atherosclerosis. Similar to defective autophagy in VSMCs, impaired autophagy in ECs has a major effect on vascular function. Decreased autophagy in ECs is associated with downregulation of eNOS and a reduction in arterial endothelium-dependent dilatation (EDD), indicating that autophagy preserves endothelial function by increasing NO bioavailability (LaRocca et al., 2012). Importantly, mounting evidence indicates that induction of autophagy could be a gamechanger in the treatment of arterial stiffness and endothelial dysfunction (De Munck et al., 2020a). The natural autophagy enhancer spermidine, for example, restores NO-mediated EDD, normalizes arterial PWV and reduces blood pressure (LaRocca et al., 2013; Eisenberg et al., 2017). This outcome is associated with enhanced expression of autophagy markers in the arterial wall such as the autophagosomal marker LC3-II and the core autophagy machinery protein Atg3. Autophagy inducer trehalose elicits similar vascular- and cardioprotective effects (LaRocca et al., 2012).

Apart from the protective effects of autophagy against arterial stiffness and the interaction of the latter with AD, autophagy represents an important mechanism to clear toxic accumulation of misfolded proteins and dysfunctional organelles in the brain. It is worthwhile to mention that loss of the essential autophagy gene Atg5 causes neonatal lethality, yet Atg5-null neonates can survive if autophagy is restored in neurons (Yoshii et al., 2016), which confirms the major importance of autophagy in the brain. Consistent with this finding, impairment of autophagy is often associated with neurodegenerative disorders, including $\mathrm{AD}$ (Fujikake et al., 2018). Interestingly, $\mathrm{A} \beta 1-40$, which is the predominant component of cerebrovascular amyloid, inhibits proliferation of human brain vascular ECs through the induction of autophagy (Hayashi et al., 2009), and may explain the reduced vessel density and hypoperfusion of the hippocampus that characterize the initial stages of AD. This finding illustrates the complex role of autophagy (causative, protective or just a consequence of the disease) in AD (Liu and Li, 2019), and indicates that autophagy should be either induced or inhibited to prevent further development of $\mathrm{AD}$, depending on the stage of the disease and type of target cells.

\section{Insulin Resistance}

Insulin resistance is a pathological condition in which cells fail to respond to insulin so that the cellular uptake of glucose does not occur. Although IR is closely correlated to Type 2 diabetes mellitus (T2M) (Sampath Kumar et al., 2019), IR has also been established in non-diabetic individuals (Catena et al., 2015; Fu et al., 2017). In addition, IR is associated with cardiovascular morbidity and mortality (Ormazabal et al., 2018; Adeva-Andany et al., 2019; Markus et al., 2019). Although the underlying mechanisms explaining this relationship are not yet understood, arterial stiffness seems to be involved. Indeed, several observational and cross-sectional studies show a correlation between IR and arterial stiffness in (non-)diabetic persons with or without hypertension in different age groups, sometimes even prior to the development of glucose intolerance (Tounian et al., 2001; Seo et al., 2005; Agnoletti et al., 2013; Fang et al., 2014; Catena et al., 2015; Fu et al., 2017; Won et al., 2018; Markus et al., 2019). Moreover, obesity-driven IR has been shown to be an independent risk factor of diabetic vasculopathy and arterial stiffness (Jia and Sowers, 2014).

Impairment of vascular function and increased arterial stiffness by IR is linked to increased media, ECM and perivascular tissue thickness and endothelial dysfunction. In the medial layer 
of the arterial wall, insulin metabolic signaling normally leads to VSMC vasodilation meaning that IR leads to the impairment of vascular relaxation (Olver et al., 2019) and thus, endothelial function which is strengthened by both in vitro (Lee et al., 2012) and in vivo experiments (Doronzo et al., 2004; Lee et al., 2009). More specifically, the latter observations were accompanied by greater concentrations of ROS and impaired activation of NO signaling pathways (Padilla et al., 2015). Furthermore, stimulation of ECs and VSMCs by angiotensin and aldosterone leads to impaired insulin-mediated vasodilation through phosphorylation of insulin receptor substrate 1 (Cote et al., 2013). In addition, increased deposition and ECM remodeling have been reported in diet-induced obese conditions associated with IR (Kang et al., 2014; Williams et al., 2015). Outside of the arterial wall, most arteries comprise perivascular adipose tissue as a structural component and an abundant source of molecular paracrine function (Villacorta and Chang, 2015). In the context of IR, adipocyte hyperplasia occurs by the decreased expression of anti-inflammatory factors and the infiltration of pro-inflammatory immune cells in the perivascular adipose tissue (Aroor et al., 2013). As such, the Framingham Offspring and Third Generation cohorts illustrated a correlation between perivascular adipose tissue volume, aortic dimensions, and arterial stiffness (Thanassoulis et al., 2012; Figure 4).

Although the vasodilatory action of insulin is well-established, insulin can also constrict arteries via the autonomic nervous system. Already at modestly elevated insulin levels, an imbalance between the vasodilatory and sympatico-excitatory effects of insulin can occur (Gordin et al., 2019). One could argue that patients suffering from T2D display diminished vasoconstrictive effects because of advanced cardiovascular autonomic neuropathy (Braffett et al., 2020). It is therefore important to mention that the observed increased arterial stiffness measurements in individuals with T2D and IR might be underestimated because of a more pronounced vasodilatory effect of insulin.

As the most energy-demanding organ, the brain consumes up to $20 \%$ of glucose-derived energy in the body (Mergenthaler et al., 2013). Numerous devastating nervous conditions such as AD are characterized by neuronal energetic dyshomeostasis (Figure 4). To guarantee optimal energy management, the brain mainly obtains insulin from systemic circulating insulin although there is evidence that de novo insulin synthesis occurs in certain brain regions altogether making the brain an "insulin sensitive organ" (Banks et al., 2012). Whereas peripheral insulin predominantly acts as a metabolic regulator, the functionality of insulin in the central nervous system seems to resemble actions of the ancestral insulin protein, being a mitogenic growth factor and metabolic regulatory hormone. Banks and colleagues hypothesized that evolution of insulin's functionality might have taken a divergent path in the periphery as compared to the central nervous system (Banks et al., 2012). The occurrence of IR in the brain was recently annotated as diabetes mellitus type III (T3DM) (Leszek et al., 2017; Candasamy et al., 2020). Several neurodegenerative features have been established as a consequence of systemic IR in AD, including metabolic and mitochondrial dysfunction (increased oxidative stress) (Wilkins et al., 2014), impaired systemic insulin signaling and miRNA deregulation (formation of NFTs) (Liu et al., 2014), neuroinflammation (activation of microglia and pro-inflammatory cytokines) (Gaspar et al., 2016; Chowdhury et al., 2018), impaired leptin signaling (loss of synaptic plasticity) (Arnold et al., 2018) and accelerated $A \beta$ plaque formation (Petrov et al., 2015; Sallam et al., 2015). The interrelated link between $\mathrm{AD}$, peripheral IR and T3DM has been established but remains poorly understood (Willette et al., 2015; Pugazhenthi et al., 2017; Denver et al., 2018). It is important to note that variable hormonal resistance syndromes exist and that these syndromes can occur independently from each other in different tissues.

To date, the relationship between IR, arterial stiffening and $\mathrm{AD}$ has been poorly studied. However, we recently found peripheral IR in an early-asymptomatic phase of the disease in young $\mathrm{AD}$-relevant amyloidosis mice overexpressing the human APP with the Swedish double mutation [B6.Cg-Tg(Thy1APP)3Somm/J, referred to as APP23]. This metabolic phenotype eventually evolved into a state of hyperinsulinemia at an older age. Throughout this longitudinal study, the animals showed no features of diabetes (Hendrickx et al., 2021). Previously, increased calorie intake was seen in addition to decreased body weights in the same single-transgenic $\mathrm{AD}$ mice, as well as in triple-transgenic $\mathrm{AD}$ mice where a hypermetabolic state was thought to be responsible (Vloeberghs et al., 2008; Knight et al., 2012). Recently, an overlap was found between hypermetabolism and brain atrophy in relation to obesity in healthy subjects (Pegueroles et al., 2019). In the context of arterial stiffness, we recently measured elevated PWV values in the above-mentioned APP23 mouse model after cardiovascular phenotyping in relatively young animals (Hendrickx et al., 2020a). In both studies (Hendrickx et al., 2020a; Hendrickx et al., 2021), animals demonstrated increased serum corticosterone levels at all ages compared to control littermates. In addition to what has previously been assumed (Vloeberghs et al., 2008; Knight et al., 2012), we hypothesize that the circulating stress hormone levels are the driving force for the development of hypermetabolism. The involvement of stress in the AD pathology has been extensively demonstrated and is now considered to be an important risk-factor of the disease (Bisht et al., 2018; Caruso et al., 2018; Dong and Csernansky, 2019). Hypermetabolism is known to be associated with IR (Willette et al., 2015; Gauglitz et al., 2008) and CVD (Clifton et al., 1981; Tulla et al., 1991). In this way, the mechanistic convergence of IR between arterial stiffness and $\mathrm{AD}$ could be explained as a cause of stress-driven hypermetabolism.

\section{CONCLUSION AND FUTURE PERSPECTIVES}

Aging is a ubiquitous multifaceted biological process that represents a high-risk factor for many major disorders including CVD (e.g., arterial stiffness) and neurodegenerative disorders (e.g., AD). The process of aging is accompanied with increasing cortisol levels leading to chronic low-grade inflammation. Given their age-related nature, it is more than likely that the mechanistic convergence between arterial stiffness and $\mathrm{AD}$ is based on this 
inflammaging phenomenon. Apart from some lifestyle changes, no disease-modifying treatments are yet available for arterial stiffness and AD. From a future perspective, it is first of all important to consistently monitor features of inflammaging and to measure arterial stiffness early in clinical practice to diagnose and stop the progression of arterial stiffness and ultimately AD. Since a complex sequence of biological events seems to underlie the development of AD by arterial stiffness, it is very challenging to create an effective precision therapeutic treatment. Although precision medicine is still in its infancy, recent scientific efforts have already facilitated the elucidation of disease diagnosis and progression, as well as biomarker discovery through the combined use of "omics"-approaches and highdimensionality data analysis (Hendrickx et al., 2020b). Finally, we argue that different forms of inflammaging bridge arterial stiffness and $\mathrm{AD}$ and that their early detection is important to timely intervene in the devastating pathological aging present in arterial stiffness and AD.

\section{REFERENCES}

Accardi, G., Aiello, A., Gambino, C. M., Virruso, C., Caruso, C., and Candore, G. (2016). Mediterranean nutraceutical foods: Strategy to improve vascular ageing. Mech. Ageing Dev. 159, 63-70. doi: 10.1016/j.mad.2016.02.007

Adeva-Andany, M. M., Martinez-Rodriguez, J., Gonzalez-Lucan, M., FernandezFernandez, C., and Castro-Quintela, E. (2019). Insulin resistance is a cardiovascular risk factor in humans. Diabetes Metab. Syndr. 13, 1449-1455.

Adlam, D., Bendall, J., De Bono, J., Alp, N., Khoo, J., Nicoli, T., et al. (2007). Relationships between nitric oxide-mediated endothelial function, eNOS coupling and blood pressure revealed by eNOS-GTP cyclohydrolase 1 double transgenic mice. Exp. Physiol. 92, 119-126. doi: 10.1113/expphysiol.2006. 035113

Agnoletti, D., Lieber, A., Zhang, Y., Protogerou, A. D., Borghi, C., Blacher, J., et al. (2013). Central hemodynamic modifications in diabetes mellitus. Atherosclerosis 230, 315-321. doi: 10.1016/j.atherosclerosis.2013. 07.054

Ahmad, M. H., Rizvi, M. A., Fatima, M., and Mondal, A. C. (2020). Pathophysiological implications of neuroinflammation mediated HPA axis dysregulation in the prognosis of cancer and depression. Mol. Cell. Endocrinol. 520:111093. doi: 10.1016/j.mce.2020.111093

Al-Zaiti, S., Saba, S., Pike, R., Williams, J., and Khraim, F. (2018). Arterial stiffness is associated with QTc interval prolongation in patients with heart failure. Biol. Res. Nurs. 20, 255-263. doi: 10.1177/1099800417737835

AlzForum (2020). Mutations. Available online at: https://www.alzforum.org/ mutations (accessed December 12 2020)

AlzGene (2020a). APOE. Available online at: http://www.alzgene.org/ geneoverview.asp? geneid=85 (accessed December 12 2020)

AlzGene (2020b). AlzGene. Available online at: http://www.alzgene.org/. (accessed December 22 2020)

Alzheimer's Association (2015). 2015 Alzheimer's disease facts and figures. Alzheimers Dement. 11, 332-384. doi: 10.1016/j.jalz.2015.02.003

Anderson, S. T., Commins, S., Moynagh, P. N., and Coogan, A. N. (2015). Lipopolysaccharide-induced sepsis induces long-lasting affective changes in the mouse. Brain Behav. Immun. 43, 98-109. doi: 10.1016/j.bbi.2014. 07.007

Arai, H., Takahashi, M., Nakajima, K., Oishi, S., and Miyaoka, H. (2018). Relationships of white matter hyperintensity with arterial stiffness and lifestyle in patients with mild cognitive impairment. Kitasato Med. J. 48, 73-80.

Arnold, S. E., Arvanitakis, Z., Macauley-Rambach, S. L., Koenig, A. M., Wang, H. Y., Ahima, R. S., et al. (2018). Brain insulin resistance in type 2 diabetes and Alzheimer disease: concepts and conundrums. Nat. Rev. Neurol. 14, 168-181. doi: 10.1038/nrneurol.2017.185

\section{AUTHOR CONTRIBUTIONS}

JH, WM, DV, and GD contributed to the writing and editing of this manuscript. All authors contributed to the article and approved the submitted version.

\section{FUNDING}

This work was supported by the University of Antwerp (GOABOF, grant 33931 and iBOF, grant iBOF-21-053) and The Reasearch Foundation - Flanders (FWO, grant G053218N).

\section{ACKNOWLEDGMENTS}

The authors are grateful to Bronwen Martin for critical reading of the manuscript. Figures were created with BioRender.com.

Arnold, S. E., Hyman, B. T., Flory, J., Damasio, A. R., and Van Hoesen, G. W. (1991). The topographical and neuroanatomical distribution of neurofibrillary tangles and neuritic plaques in the cerebral cortex of patients with Alzheimer's disease. Cereb. Cortex 1, 103-116. doi: 10.1093/cercor/1. 1.103

Aroor, A. R., Jia, G., and Sowers, J. R. (2018). Cellular mechanisms underlying obesity-induced arterial stiffness. Am. J. Physiol. Regul. Integr. Comp. Physiol. 314, R387-R398.

Aroor, A. R., McKarns, S., Demarco, V. G., Jia, G., and Sowers, J. R. (2013). Maladaptive immune and inflammatory pathways lead to cardiovascular insulin resistance. Metabolism 62, 1543-1552. doi: 10.1016/j.metabol.2013. 07.001

Asamoah, S., Siegler, J., Chang, D., Scholey, A., Yeung, A., and Cheema, B. S. (2013). Effect of aerobic training on cognitive function and arterial stiffness in sedentary young adults: a pilot randomized controlled trial. Physiol. J. 2013, 847325.

Austin, S. A., d'Uscio, L. V., and Katusic, Z. S. (2013). Supplementation of nitric oxide attenuates AbetaPP and BACE1 protein in cerebral microcirculation of eNOS-deficient mice. Journal of Alzheimer's disease 33, 29-33. doi: 10.3233/ jad-2012-121351

Austin, S. A., and Katusic, Z. S. (2016). Loss of endothelial nitric oxide synthase promotes p25 generation and tau phosphorylation in a murine model of Alzheimer's disease. Circ. Res. 119, 1128-1134. doi: 10.1161/circresaha.116. 309686

Austin, S. A., and Katusic, Z. S. (2020). Partial loss of endothelial nitric oxide leads to increased cerebrovascular beta amyloid. J. Cereb. Blood Flow Metab. 40, 392-403. doi: 10.1177/0271678x188 22474

Baek, H., Lee, C. J., Choi, D. B., Kim, N. S., Kim, Y. S., Ye, Y. J., et al. (2018). Bee venom phospholipase A2 ameliorates Alzheimer's disease pathology in Abeta vaccination treatment without inducing neuro-inflammation in a $3 \times \mathrm{Tg}$-AD mouse model. Sci. Rep. 8:17369.

Bailey, A. J. (2001). Molecular mechanisms of ageing in connective tissues. Mech. Ageing Dev. 122, 735-755. doi: 10.1016/s0047-6374(01)00225-1

Bailey, D. M., Rimoldi, S. F., Rexhaj, E., Pratali, L., Salmòn, C. S., Villena, M., et al. (2013). Oxidative-nitrosative stress and systemic vascular function in highlanders with and without exaggerated hypoxemia. Chest 143, 444-451. doi: $10.1378 /$ chest.12-0728

Balaiya, S., and Chalam, K. V. (2014). An in vitro assay to quantify nitrosative component of oxidative stress. J. Mol. Genet. Med. 8:120.

Banks, W. A., Owen, J. B., and Erickson, M. A. (2012). Insulin in the brain: there and back again. Pharmacol. Ther. 136, 82-93. doi: 10.1016/j.pharmthera.2012. 07.006 
Baruch, K., Rosenzweig, N., Kertser, A., Deczkowska, A., Sharif, A. M., Spinrad, A., et al. (2015). Breaking immune tolerance by targeting Foxp3(+) regulatory $\mathrm{T}$ cells mitigates Alzheimer's disease pathology. Nat. Commun. 6:7967.

Bateman, R. J., Aisen, P. S., De Strooper, B., Fox, N. C., Lemere, C. A., Ringman, J. M., et al. (2011). Autosomal-dominant Alzheimer's disease: a review and proposal for the prevention of Alzheimer's disease. Alzheimers Res. Ther. 3, $1-13$.

Bauer, V., and Sotníková, R. (2010). Nitric oxide-the endothelium-derived relaxing factor and its role in endothelial functions. Gen. Physiol. Biophys. 29:319. doi: 10.4149/gpb_2010_04_319

Beauchesne, E., Desjardins, P., Hazell, A. S., and Butterworth, R. F. (2009). eNOS gene deletion restores blood-brain barrier integrity and attenuates neurodegeneration in the thiamine-deficient mouse brain. J. Neurochem. 111, 452-459. doi: 10.1111/j.1471-4159.2009.06338.x

Ben-Shlomo, Y., Spears, M. R., Boustred, C., May, M., Anderson, S. G., Benjamin, E. J., et al. (2014). Aortic pulse wave velocity improves cardiovascular event prediction: an individual participant meta-analysis of prospective? observational data from 17,635 subjects. J. Am. College Cardiol. 63, 636-646.

Bernatova, I., Puzserova, A., Balis, P., Sestakova, N., Horvathova, M., Kralovicova, Z., et al. (2018). Chronic stress produces persistent increases in plasma corticosterone, reductions in brain and cardiac nitric oxide production, and delayed alterations in endothelial function in young prehypertensive rats. Front. Physiol. 9:1179. doi: 10.3389/fphys.2018. 01179

Bernstein, D. L., Zuluaga-Ramirez, V., Gajghate, S., Reichenbach, N. L., Polyak, B., Persidsky, Y., et al. (2020). miR-98 reduces endothelial dysfunction by protecting blood-brain barrier $(\mathrm{BBB})$ and improves neurological outcomes in mouse ischemia/reperfusion stroke model. J. Cereb. Blood Flow Metab. 40, 1953-1965. doi: 10.1177/0271678x19882264

Beyar, R., Yin, F. C. P., Hausknecht, M. J., Weisfeldt, M. L., and Kass, D. A. (1989). Dependence of left ventricular twist-radial shortening relations on cardiac cycle phase. Am. J. Physiol. 257(Pt 2), H1119-H1126.

Bisht, K., Sharma, K., and Tremblay, M. -È (2018). Chronic stress as a risk factor for Alzheimer's disease: roles of microglia-mediated synaptic remodeling, inflammation, and oxidative stress. Neurobiol. Stress 9, 9-21. doi: 10.1016/j. ynstr.2018.05.003

Bose, G., Graveline, J., Yogendrakumar, V., Fergusson, D., and Dowlatshahi, D. (2019). Direct oral anticoagulants in treatment of cerebral venous thrombosis: a systematic review protocol. Syst. Rev. 8, 1-4.

Bouvier, D. S., and Murai, K. K. (2015). Synergistic actions of microglia and astrocytes in the progression of Alzheimer's disease. J. Alzheimers Dis. 45, 1001-1014. doi: 10.3233/jad-143156

Braak, H., and Braak, E. (1991). Neuropathological stageing of Alzheimer-related changes. Acta Neuropathol. 82, 239-259. doi: 10.1007/bf00308809

Braffett, B. H., Gubitosi-Klug, R. A., Albers, J. W., Feldman, E. L., Martin, C. L., White, N. H., et al. (2020). Risk factors for diabetic peripheral neuropathy and cardiovascular autonomic neuropathy in the diabetes control and complications trial/epidemiology of diabetes interventions and complications (DCCT/EDIC) study. Diabetes 69, 1000-1010. doi: 10.2337/db19-1046

Briones, A. M., Tabet, F., Callera, G. E., Montezano, A. C., Yogi, A., He, Y., et al. (2011). Differential regulation of Nox1, Nox2 and Nox4 in vascular smooth muscle cells from WKY and SHR. J. Am. Soc. Hypertens. 5, 137-153. doi: 10.1016/j.jash.2011.02.001

Burgaletto, C., Munafo, A., Di Benedetto, G., De Francisci, C., Caraci, F., Di Mauro, R., et al. (2020). The immune system on the TRAIL of Alzheimer's disease. J. Neuroinflamm. 17:298.

Burke, S. J., Batdorf, H. M., Eder, A. E., Karlstad, M. D., Burk, D. H., Noland, R. C., et al. (2017). Oral corticosterone administration reduces insulitis but promotes insulin resistance and hyperglycemia in male nonobese diabetic mice. Am. J. Pathol. 187, 614-626. doi: 10.1016/j.ajpath.2016.11.009

Cambronero, F. E., Liu, D., Neal, J. E., Moore, E. E., Gifford, K. A., Terry, J. G., et al. (2018). APOE genotype modifies the association between central arterial stiffening and cognition in older adults. Neurobiol. Aging 67, 120-127. doi: 10.1016/j.neurobiolaging.2018.02.009

Candasamy, M., Mohamed Elhassan, S. A., Kumar Bhattamisra, S., Hua, W. Y., Sern, L. M., Binti Busthamin, N. A., et al. (2020). Type 3 diabetes (Alzheimer's disease): new insight for promising therapeutic avenues. Panminerva Med. 62, $155-163$.

Canobbio, I., Abubaker, A. A., Visconte, C., Torti, M., and Pula, G. (2015). Role of amyloid peptides in vascular dysfunction and platelet dysregulation in Alzheimer's disease. Front. Cell. Neurosci. 9:65. doi: 10.3389/fncel.2015. 00065

Carrano, A., Hoozemans, J. J., van der Vies, S. M., Rozemuller, A. J., van Horssen, J., and de Vries, H. E. (2011). Amyloid beta induces oxidative stress-mediated blood-brain barrier changes in capillary amyloid angiopathy. Antioxid. Redox Signal. 15, 1167-1178. doi: 10.1089/ars.2011.3895

Carrano, A., Hoozemans, J. J., Van Der Vies, S. M., Van Horssen, J., De Vries, H. E., and Rozemuller, A. J. (2012). Neuroinflammation and blood-brain barrier changes in capillary amyloid angiopathy. Neurodegen. Dis. 10, 329-331. doi: $10.1159 / 000334916$

Caruso, A., Nicoletti, F., Mango, D., Saidi, A., Orlando, R., and Scaccianoce, S. (2018). Stress as risk factor for Alzheimer's disease. Pharmacol. Res. 132, $130-134$.

Catena, C., Colussi, G., Frangipane, A., Russo, A., Verheyen, N. D., and Sechi, L. A. (2015). Carotid artery stiffness is related to hyperinsulinemia and insulin-resistance in middle-aged, non-diabetic hypertensive patients. Nutr. Metab. Cardiovasc. Dis. 25, 968-974. doi: 10.1016/j.numecd.2015. 06.009

Cengiz, M., Yavuzer, S., K $\iota l ı c ̧ k \iota$ ran Avcı, B., Yürüyen, M., Yavuzer, H., Dikici, S. A., et al. (2015). Circulating miR-21 and eNOS in subclinical atherosclerosis in patients with hypertension. Clin. Exp. Hypertens. 37, 643-649. doi: 10.3109/ 10641963.2015.1036064

Chadwick, W., Martin, B., Chapter, M. C., Park, S.-S., Wang, L., Daimon, C. M., et al. (2012). GIT2 acts as a potential keystone protein in functional hypothalamic networks associated with age-related phenotypic changes in rats. PLoS One 7:e36975. doi: 10.1371/journal.pone.0036975

Chau, N. P., Coleman, T. G., London, G. M., and Safar, M. E. (1982). Meaning of the cardiac output-blood volume relationship in essential hypertension. Am. J. Physiol. 243, R318-R328.

Chen, J., Gao, Q., Jiang, L., Feng, X., Zhu, X., Fan, X., et al. (2017). The NOX2derived reactive oxygen species damaged endothelial nitric oxide system via suppressed BKCa/SKCa in preeclampsia. Hypertens. Res. 40, 457-464. doi: $10.1038 / \mathrm{hr} .2016 .180$

Chen, K., and Sun, Z. (2019). Autophagy plays a critical role in Klotho gene deficiency-induced arterial stiffening and hypertension. J. Mol. Med. 97, 16151625. doi: 10.1007/s00109-019-01841-6

Chen, M., Inestrosa, N. C., Ross, G. S., and Fernandez, H. L. (1995). Platelets are the primary source of amyloid $\beta$-peptide in human blood. Biochem. Biophys. Res. Commun. 213, 96-103. doi: 10.1006/bbrc.1995.2103

Chen, W. R., Zhou, Y. J., Yang, J. Q., Liu, F., Zhao, Y. X., and Sha, Y. (2019). Melatonin attenuates beta-glycerophosphate-induced calcification of vascular smooth muscle cells via a Wnt1/beta-catenin signaling pathway. BioMed Res. Int. 2019:3139496.

Cheng, L., Wang, L., Guo, M., He, J., Deng, Y., Liu, J., et al. (2020). Clinically relevant high levels of human C-reactive protein induces endothelial dysfunction and hypertension by inhibiting the AMPK-eNOS axis. Clin. Sci. 134, 1805-1819. doi: 10.1042/cs20200137

Cheng, M., Li, B. Y., Li, X. L., Wang, Q., Zhang, J. H., Jing, X. J., et al. (2012). Correlation between serum lactadherin and pulse wave velocity and cardiovascular risk factors in elderly patients with type 2 diabetes mellitus. Diab. Res. Clin. Pract. 95, 125-131. doi: 10.1016/j.diabres.2011. 09.030

Chiang, H. Y., Chu, P. H., and Lee, T. H. (2019). MFG-E8 mediates arterial aging by promoting the proinflammatory phenotype of vascular smooth muscle cells. J. Biomed. Sci. 26:61.

Chiba, T., Sakuma, K., Komatsu, T., Cao, X., Aimoto, M., Nagasawa, Y., et al. (2019). Physiological role of nitric oxide for regulation of arterial stiffness in anesthetized rabbits. J. Pharmacol. Sci. 139, 42-45. doi: 10.1016/j.jphs.2018. 11.003

Chowdhury, A. A., Gawali, N. B., Munshi, R., and Juvekar, A. R. (2018). Trigonelline insulates against oxidative stress, proinflammatory cytokines and restores BDNF levels in lipopolysaccharide induced cognitive impairment in adult mice. Metab. Brain Dis. 33, 681-691. doi: 10.1007/s11011-017-0147-5 
Ciccocioppo, F., Lanuti, P., Pierdomenico, L., Simeone, P., Bologna, G., Ercolino, E., et al. (2019). The characterization of regulatory T-cell profiles in Alzheimer's disease and multiple sclerosis. Sci. Rep. 9:8788.

Cifuentes, D., Poittevin, M., Bonnin, P., Ngkelo, A., Kubis, N., MerkulovaRainon, T., et al. (2017). Inactivation of nitric oxide synthesis exacerbates the development of Alzheimer disease pathology in APPPS1 mice (Amyloid Precursor Protein/Presenilin-1). Hypertension 70, 613-623. doi: 10.1161/ hypertensionaha.117.09742

Clifton, G. L., Ziegler, M. G., and Grossman, R. G. (1981). Circulating catecholamines and sympathetic activity after head injury. Neurosurgery 8, 10-14. doi: 10.1227/00006123-198101000-00003

Cooper, L. L., and Mitchell, G. F. (2016). Aortic stiffness, cerebrovascular dysfunction, and memory. Pulse 4, 69-77. doi: 10.1159/000448176

Cote, A. T., Harris, K. C., Panagiotopoulos, C., Sandor, G. G., and Devlin, A. M. (2013). Childhood obesity and cardiovascular dysfunction. J. Am. Coll. Cardiol. 62, 1309-1319.

Coutinho, T., Turner, S. T., and Kullo, I. J. (2011). Aortic pulse wave velocity is associated with measures of subclinical target organ damage. JACC Cardiovasc. Imag. 4, 754-761. doi: 10.1016/j.jcmg.2011.04.011

Cozma, A., Sitar-Taut, A., Orăşan, O., Leucuta, D., Alexescu, T., Stan, A., et al. (2018). Determining factors of arterial stiffness in subjects with metabolic syndrome. Metab. Syndr. Relat. Disord. 16, 490-496. doi: 10.1089/met.2018. 0057

Cras, P., Kawai, M., Siedlak, S., and Perry, G. (1991). Microglia are associated with the extracellular neurofibrillary tangles of Alzheimer disease. Brain Res. 558, 312-314. doi: 10.1016/0006-8993(91)90783-r

Csiszar, A., Sosnowska, D., Wang, M., Lakatta, E. G., Sonntag, W. E., and Ungvari, Z. (2012). Age-associated proinflammatory secretory phenotype in vascular smooth muscle cells from the non-human primate Macaca mulatta: reversal by resveratrol treatment. J. Gerontol. A Biol. Sci. Med. Sci. 67, 811-820. doi: 10.1093 /gerona/glr228

Dansokho, C., Ait Ahmed, D., Aid, S., Toly-Ndour, C., Chaigneau, T., Calle, V., et al. (2016). Regulatory $\mathrm{T}$ cells delay disease progression in Alzheimer-like pathology. Brain 139, 1237-1251. doi: 10.1093/brain/awv408

De Duve, C., and Wattiaux, R. (1966). Functions of lysosomes. Annu. Rev. Physiol. 28, 435-492. doi: 10.1146/annurev.ph.28.030166. 002251

De Meyer, G. R. Y., Grootaert, M. O., Michiels, C. F., Kurdi, A., Schrijvers, D. M., and Martinet, W. (2015). Autophagy in vascular disease. Circ. Res. 116, 468-479.

De Munck, D. G., De Meyer, G. R. Y., and Martinet, W. (2020a). Autophagy as an emerging therapeutic target for age-related vascular pathologies. Expert. Opin. Ther. Targets 24, 131-145. doi: 10.1080/14728222.2020.1723079

De Munck, D. G., De Moudt, S., Roth, L., De Meyer, G. R. Y., Martinet, W., and Fransen, P. (2020b). Defective autophagy in vascular smooth muscle cells alters vascular reactivity of the mouse femoral artery. Front. Physiol. 11:548943. doi: 10.3389/fphys.2020.548943

De Munck, D. G., Leloup, A. J. A., De Meyer, G. R. Y., Martinet, W., and Fransen, P. (2020c). Defective autophagy in vascular smooth muscle cells increases passive stiffness of the mouse aortic vessel wall. Pflugers Arch. 472, 1031-1040. doi: 10.1007/s00424-020-02408-y

Degenhardt, K., Wagner, J., Skodras, A., Candlish, M., Koppelmann, A. J., Wild, K., et al. (2020). Medin aggregation causes cerebrovascular dysfunction in aging wild-type mice. Proc. Natl. Acad. Sci. U.S.A. 117, 23925-23931. doi: 10.1073/ pnas. 2011133117

Demer, L. L., and Tintut, Y. (2008). Vascular calcification: pathobiology of a multifaceted disease. Circulation 117, 2938-2948. doi: 10.1161/circulationaha. 107.743161

Denver, P., English, A., and McClean, P. L. (2018). Inflammation, insulin signaling and cognitive function in aged APP/PS1 mice. Brain Behav. Immun. 70, 423434. doi: 10.1016/j.bbi.2018.03.032

Dhananjayan, K., Gunawardena, D., Hearn, N., Sonntag, T., Moran, C., Gyengesi, E., et al. (2017). Activation of macrophages and microglia by interferon-gamma and lipopolysaccharide increases methylglyoxal production: a new mechanism in the development of vascular complications and cognitive decline in type 2 diabetes mellitus? J. Alzheimers Dis. 59, 467-479. doi: 10.3233/jad-161152

Dong, H., and Csernansky, J. G. (2019). Stress and its impact on Alzheimer's disease. Neurobiol. Stress 10:100167. doi: 10.1016/j.ynstr.2019.100167
Dong, Z.-C., Wu, M.-M., Zhang, Y.-L., Wang, Q.-S., Liang, C., Yan, X., et al. (2020). The vascular endothelial growth factor trap aflibercept induces vascular dysfunction and hypertension via attenuation of eNOS/NO signaling in mice. Acta Pharmacol. Sin. doi: 10.1038/s41401-020-00569-1 [Epub ahead of print].

Doronzo, G., Russo, I., Mattiello, L., Anfossi, G., Bosia, A., and Trovati, M. (2004). Insulin activates vascular endothelial growth factor in vascular smooth muscle cells: influence of nitric oxide and of insulin resistance. Eur. J. Clin. Invest. 34, 664-673. doi: 10.1111/j.1365-2362.2004.01412.x

Dow, P. (1940). Adriaan Isebree Moens (1847-1891). Yale J. Biol. Med. 12, 243-250.

Dregan, A. (2018). Arterial stiffness association with chronic inflammatory disorders in the UK Biobank study. Heart 104, 1257-1262. doi: 10.1136/ heartjnl-2017-312610

Dubey, H., Gulati, K., and Ray, A. (2020). Alzheimer's disease: a contextual link with nitric oxide synthase. Curr. Mol. Med. 20, 505-515. doi: 10.2174/ 1566524019666191129103117

Durham, A. L., Speer, M. Y., Scatena, M., Giachelli, C. M., and Shanahan, C. M. (2018). Role of smooth muscle cells in vascular calcification: implications in atherosclerosis and arterial stiffness. Cardiovasc. Res. 114, 590-600. doi: 10. 1093/cvr/cvy010

Eastwood, R., Amaducci, L., Brayne, C., Broc, T., and Jolles, J. (1996). The challenge of the dementias. Lancet 347, 1303-1307. doi: 10.1016/s0140-6736(96)90943-5

Eisenberg, T., Abdellatif, M., Zimmermann, A., Schroeder, S., Pendl, T., Harger, A., et al. (2017). Dietary spermidine for lowering high blood pressure. Autophagy 13, 767-769.

El Khoury, J., Hickman, S., Thomas, C., Loike, J., and Silverstein, S. (1998). Microglia, scavenger receptors, and the pathogenesis of Alzheimer's disease. Neurobiol. Aging 19, S81-S84.

Ezaki, J., Matsumoto, N., Takeda-Ezaki, M., Komatsu, M., Takahashi, K., Hiraoka, Y., et al. (2011). Liver autophagy contributes to the maintenance of blood glucose and amino acid levels. Autophagy 7, 727-736. doi: 10.4161/auto.7.7. 15371

Fang, F.-S., Liu, M.-Y., Cheng, X.-L., Zhong, W.-W., Miao, X.-Y., Li, J., et al. (2014). Insulin resistance correlates with the arterial stiffness before glucose intolerance. Intern. Med. 53, 189-194. doi: 10.2169/internalmedicine.53.0690

Foidl, B. M., Oberacher, H., Marksteiner, J., and Humpel, C. (2020). Platelet and plasma phosphatidylcholines as biomarkers to diagnose cerebral amyloid angiopathy. Front. Neurol. 11:359. doi: 10.3389/fneur.2020.00359

Folkow, B., and Svanborg, A. (1993). Physiology of cardiovascular aging. Physiol. Rev. 73, 725-764. doi: 10.1152/physrev.1993.73.4.725

Franceschi, C., and Campisi, J. (2014). Chronic inflammation (inflammaging) and its potential contribution to age-associated diseases. J. Gerontol. Ser. A Biomed. Sci. Med. Sci. 69, S4-S9.

Franceschi, C., Capri, M., Monti, D., Giunta, S., Olivieri, F., Sevini, F., et al. (2007). Inflammaging and anti-inflammaging: a systemic perspective on aging and longevity emerged from studies in humans. Mech. Ageing Dev. 128, 92-105. doi: 10.1016/j.mad.2006.11.016

Fu, S., Lin, Y., Luo, L., and Ye, P. (2017). Relationship between central arterial stiffness and insulin resistance in chinese community-dwelling population without diabetes mellitus. Int. J. Endocrinol. 2017:1073919.

Fu, Z., Wang, M., Gucek, M., Zhang, J., Wu, J., Jiang, L., et al. (2009). Milk fat globule protein epidermal growth factor-8: a pivotal relay element within the angiotensin II and monocyte chemoattractant protein-1 signaling cascade mediating vascular smooth muscle cells invasion. Circul. Res. 104, 1337-1346. doi: $10.1161 /$ circresaha. 108.187088

Fujikake, N., Shin, M., and Shimizu, S. (2018). Association between autophagy and neurodegenerative diseases. Front. Neurosci. 12:255. doi: 10.3389/fnins.2018. 00255

Fukami, H., Morinaga, J., Okadome, Y., Nishiguchi, Y., Iwata, Y., Kanki, T., et al. (2020). Circulating angiopoietin-like protein 2 levels and arterial stiffness in patients receiving maintenance hemodialysis: a cross-sectional study. Atherosclerosis 315, 18-23. doi: 10.1016/j.atherosclerosis.2020.10.890

Furman, J. L., Vaquer-Alicea, J., White, C. L. III, Cairns, N. J., Nelson, P. T., and Diamond, M. I. (2017). Widespread tau seeding activity at early Braak stages. Acta Neuropathol. 133, 91-100. doi: 10.1007/s00401-0161644-Z

Galis, Z. S., and Khatri, J. J. (2002). Matrix metalloproteinases in vascular remodeling and atherogenesis: the good, the bad, and the ugly. Circ. Res. 90, 251-262. doi: $10.1161 /$ res.90.3.251 
Gaspar, J. M., Baptista, F. I., Macedo, M. P., and Ambrosio, A. F. (2016). Inside the diabetic brain: role of different players involved in cognitive decline. ACS Chem. Neurosci. 7, 131-142. doi: 10.1021/acschemneuro.5b00240

Gate, D., Saligrama, N., Leventhal, O., Yang, A. C., Unger, M. S., Middeldorp, J., et al. (2020). Clonally expanded CD8 T cells patrol the cerebrospinal fluid in Alzheimer's disease. Nature 577, 399-404. doi: 10.1038/s41586-019-1895-7

Gauglitz, G. G., Herndon, D. N., and Jeschke, M. G. (2008). Insulin resistance postburn: underlying mechanisms and current therapeutic strategies. J. Burn Care Res. 29, 683-694. doi: 10.1097/bcr.0b013e31818481ce

GBD 2016 Neurology Collaborators (2019). Global, regional, and national burden of neurological disorders, 1990-2016: a systematic analysis for the Global Burden of Disease Study 2016. Lancet Neurol. 18, 459-480.

Germolec, D. R., Shipkowski, K. A., Frawley, R. P., and Evans, E. (2018). Markers of Inflammation. In Immunotoxicity Testing. Berlin: Springer, 57-79.

Giunta, B., Fernandez, F., Nikolic, W. V., Obregon, D., Rrapo, E., Town, T., et al. (2008). Inflammaging as a prodrome to Alzheimer's disease. J. Neuroinflamm. 5, 1-15. doi: 10.2174/1567211212225942050

Gordin, D., Saraheimo, M., Tuomikangas, J., Soro-Paavonen, A., Forsblom, C., Paavonen, K., et al. (2019). Insulin exposure mitigates the increase of arterial stiffness in patients with type 2 diabetes and albuminuria: an exploratory analysis. Acta Diabetol. 56, 1169-1175. doi: 10.1007/s00592-019-01351-4

Greenwald, S. E. (2007). Ageing of the conduit arteries. J. Pathol. 211, 157-172. doi: $10.1002 /$ path.2101

Grootaert, M. O., da Costa Martins, P. A., Bitsch, N., Pintelon, I., De Meyer, G. R. Y., Martinet, W., et al. (2015). Defective autophagy in vascular smooth muscle cells accelerates senescence and promotes neointima formation and atherogenesis. Autophagy 11, 2014-2032. doi: 10.1080/15548627.2015.1096485

Guerrero, J. (2017). Understanding cortisol action in acute inflammation: a view from the adrenal gland to the target cell. Revist. Med. Chile 145, 230-239.

Guven, G., Bilgic, B., Samanci, B., Gurvit, H., Hanagasi, H., Donmez, C., et al. (2020). Peripheral TREM2 mRNA levels in early and late-onset Alzheimer disease's patients. Mol. Biol. Rep. 47, 5903-5909. doi: 10.1007/s11033-02005661-7

Haass, C., and De Strooper, B. (1999). The presenilins in Alzheimer's diseaseproteolysis holds the key. Science 286, 916-919. doi: 10.1126/science.286. 5441.916

Han, B. H., Zhou, M.-L., Johnson, A. W., Singh, I., Liao, F., Vellimana, A. K., et al. (2015). Contribution of reactive oxygen species to cerebral amyloid angiopathy, vasomotor dysfunction, and microhemorrhage in aged Tg2576 mice. Proc. Natl. Acad. Sci. U.S.A. 112, E881-E890.

Hardy, J. (1995). Apolipoprotein E in the genetics and epidemiology of Alzheimer's disease. Am. J. Med. Genet. 60, 456-460.

Hardy, J. (1997). Amyloid, the presenilins and Alzheimer's disease. Trends Neurosci. 20, 154-159. doi: 10.1016/s0166-2236(96)01030-2

Haselden, W. D., Kedarasetti, R. T., and Drew, P. J. (2020). Spatial and temporal patterns of nitric oxide diffusion and degradation drive emergent cerebrovascular dynamics. PLoS Comput. Biol. 16:e1008069. doi: 10.1371/ journal.pcbi.1008069

Hayashi, S., Sato, N., Yamamoto, A., Ikegame, Y., Nakashima, S., Ogihara, T., et al. (2009). Alzheimer disease-associated peptide, amyloid beta40, inhibits vascular regeneration with induction of endothelial autophagy. Arterioscler. Thromb. Vasc. Biol. 29, 1909-1915. doi: 10.1161/atvbaha.109.188516

Hendrickx, J. O., De Moudt, S., Calus, E., Van Dam, D., and De Meyer, G. R. Y. (2021). "Transient peripheral insulin resistance in a mutated hAPP overexpressing mouse model of Alzheimer's disease," in Proceedings of the 15th International Conference on Alzheimer's and Parkinson's Diseases: Mechanisms, Clinical Strategies and promising Treatments of Neurodegenerative Diseases (Barcelona).

Hendrickx, J. O., De Moudt, S., Van Dam, D., De Meyer, G. R. Y., and Fransen, P. (2020a). Cardiovascular phenotyping of the APP23 overexpressing mouse model of Alzheimer's disease reveals decreased vascular contractility. Circulation 142:A15515.

Hendrickx, J. O., van Gastel, J., Leysen, H., Martin, B., and Maudsley, S. (2020b). High-dimensionality data analysis of pharmacological systems associated with complex diseases. Pharmacol. Rev. 72, 191-217. doi: 10.1124/pr.119.017921

Heneka, M. T., Carson, M. J., El Khoury, J., Landreth, G. E., Brosseron, F., Feinstein, D. L., et al. (2015). Neuroinflammation in Alzheimer's disease. Lancet Neurol. 14, 388-405.
Henskens, L. H. G., Van Oostenbrugge, R. J., Kroon, A. A., De Leeuw, P. W., and Lodder, J. (2008a). Brain microbleeds are associated with ambulatory blood pressure levels in a hypertensive population. Hypertension 51, 62-68. doi: 10.1161/hypertensionaha.107.100610

Henskens, L. H. G., Kroon, A. A., Van Oostenbrugge, R. J., Gronenschild, E. H., Fuss-Lejeune, M. M., Hofman, P. A., et al. (2008b). Increased aortic pulse wave velocity is associated with silent cerebral small-vessel disease in hypertensive patients. Hypertension 52, 1120-1126. doi: 10.1161/hypertensionaha.108. 119024

Herranz, B., Marquez, S., Guijarro, B., Aracil, E., Aicart-Ramos, C., RodriguezCrespo, I., et al. (2012). Integrin-linked kinase regulates vasomotor function by preventing endothelial nitric oxide synthase uncoupling: role in atherosclerosis. Circ. Res. 110, 439-449. doi: 10.1161/circresaha.111.253948

Hoffman, L. B., Schmeidler, J. M., Lesser, G. T., Beeri, M. S., Purohit, D. P., Grossman, H. T., et al. (2009). Less Alzheimer disease neuropathology in medicated hypertensive than nonhypertensive persons. Neurology 72, 17201726. doi: 10.1212/01.wnl.0000345881.82856.d5

Hughes, T. M., Craft, S., and Lopez, O. L. (2015). Review of 'the potential role of arterial stiffness in the pathogenesis of Alzheimer's disease'. Neurodegen. Dis. Manag. 5, 121-135. doi: 10.2217/nmt.14.53

Hughes, T. M., Kuller, L. H., Barinas-Mitchell, E. J., Mackey, R. H., McDade, E. M., Klunk, W. E., et al. (2013). Pulse wave velocity is associated with $\beta$-amyloid deposition in the brains of very elderly adults. Neurology 81, 1711-1718. doi: 10.1212/01.wnl.0000435301.64776.37

Hughes, T. M., Kuller, L. H., Barinas-Mitchell, E. J., McDade, E. M., Klunk, W. E., Cohen, A. D., et al. (2014). Arterial stiffness and beta-amyloid progression in nondemented elderly adults. JAMA Neurol. 71, 562-568. doi: 10.1001/ jamaneurol.2014.186

Hughes, T. M., Wagenknecht, L. E., Craft, S., Mintz, A., Heiss, G., Palta, P., et al. (2018). Arterial stiffness and dementia pathology: atherosclerosis risk in communities (ARIC)-PET study. Neurology 90, e1248-e1256.

Hwang, S., and Kim, J.-K. (2018). Effects of NADPH oxidase inhibitors and mitochondria-targeted antioxidants on amyloid $\beta 1$-42-induced neuronal deaths in mouse mixed cortical cultures. Chonnam Med. J. 54:159. doi: 10.4068/ cmj.2018.54.3.159

Iadecola, C. (2017). The neurovascular unit coming of age: a journey through neurovascular coupling in health and disease. Neuron 96, 17-42. doi: 10.1016/ j.neuron.2017.07.030

Isabelle, M., Simonet, S., Ragonnet, C., Sansilvestri-Morel, P., Clavreul, N., Vayssettes-Courchay, C., et al. (2012). Chronic reduction of nitric oxide level in adult spontaneously hypertensive rats induces aortic stiffness similar to old spontaneously hypertensive rats. J. Vasc. Res. 49, 309-318. doi: 10.1159/ 000337470

Ishida, A., Fujisawa, M., del Saz, E. G., Okumiya, K., Kimura, Y., Manuaba, I. I. B., et al. (2018). Arterial stiffness, not systolic blood pressure, increases with age in native Papuan populations. Hypertens. Res. 41, 539-546. doi: 10.1038/s41440018-0047-z

Ismaeel, A., Brumberg, R. S., Kirk, J. S., Papoutsi, E., Farmer, P. J., Bohannon, W. T., et al. (2018). Oxidative stress and arterial dysfunction in peripheral artery disease. Antioxidants 7:145. doi: 10.3390/antiox7100145

Itagaki, S., McGeer, P., and Akiyama, H. (1988). Presence of T-cytotoxic suppressor and leucocyte common antigen positive cells in Alzheimer's disease brain tissue. Neurosci. Lett. 91, 259-264. doi: 10.1016/0304-3940(88) 90690-8

Itariu, B. K., and Stulnig, T. M. (2014). "Obesity, insulin resistance, and inflammaging," in Inflammation, Advancing Age and Nutrition, eds I. Rahman and D. Bagchi (Amsterdam: Elsevier), 157-164. doi: 10.1016/b978-0-12397803-5.00013-7

Iulita, M. F., Noriega de la Colina, A., and Girouard, H. (2018). Arterial stiffness, cognitive impairment and dementia: confounding factor or real risk? J. Neurochem. 144, 527-548. doi: 10.1111/jnc.14235

Jack, C. R. Jr., Bennett, D. A., Blennow, K., Carrillo, M. C., Dunn, B., Haeberlein, S. B., et al. (2018). NIA-AA research framework: toward a biological definition of Alzheimer's disease. Alzheimers Dement. 14, 535-562. doi: 10.1016/j.jalz. 2018.02.018

Jain, S., Khera, R., Corrales-Medina, V. F., Townsend, R. R., and Chirinos, J. A. (2014). Inflammation and arterial stiffness in humans. Atherosclerosis 237, 381-390. doi: 10.1016/j.atherosclerosis.2014.09.011 
Jefferson, A. L., Cambronero, F. E., Liu, D., Moore, E. E., Neal, J. E., Terry, J. G., et al. (2018). Higher aortic stiffness is related to lower cerebral blood flow and preserved cerebrovascular reactivity in older adults. Circulation 138, 1951-1962. doi: 10.1161/circulationaha.118.032410

Jensen, C. J., Massie, A., and De Keyser, J. (2013). Immune players in the CNS: the astrocyte. J. Neuroimmune Pharmacol. 8, 824-839. doi: 10.1007/s11481-0139480-6

Jia, G., and Sowers, J. R. (2014). Endothelial dysfunction potentially interacts with impaired glucose metabolism to increase cardiovascular risk. Hypertension 64, 1192-1193. doi: 10.1161/hypertensionaha.114.04348

Jiang, L., Zhang, J., Monticone, R. E., Telljohann, R., Wu, J., Wang, M., et al. (2012). Calpain-1 regulation of matrix metalloproteinase 2 activity in vascular smooth muscle cells facilitates age-associated aortic wall calcification and fibrosis. Hypertension 60, 1192-1199. doi: 10.1161/hypertensionaha.112.196840

Justice, N. J. (2018). The relationship between stress and Alzheimer's disease. Neurobiol. Stress 8, 127-133.

Kahn, M. S., Kranjac, D., Alonzo, C. A., Haase, J. H., Cedillos, R. O., McLinden, K. A., et al. (2012). Prolonged elevation in hippocampal Abeta and cognitive deficits following repeated endotoxin exposure in the mouse. Behav. Brain Res. 229, 176-184. doi: 10.1016/j.bbr.2012.01.010

Kalaria, R. N. (2010). Vascular basis for brain degeneration: faltering controls and risk factors for dementia. Nutr. Rev. 68(Suppl. 2), S74-S87.

Kalaria, R. N., Akinyemi, R., and Ihara, M. (2012). Does vascular pathology contribute to Alzheimer changes? J. Neurol. Sci. 322, 141-147. doi: 10.1016/ j.jns.2012.07.032

Kang, L., Mayes, W. H., James, F. D., Bracy, D. P., and Wasserman, D. H. (2014). Matrix metalloproteinase 9 opposes diet-induced muscle insulin resistance in mice. Diabetologia 57, 603-613. doi: 10.1007/s00125-013-3128-1

Kass, D. A., Maughan, W. L., Ciuffo, A. A., Graves, W. A., Healy, B., and Weisfeldt, M. L. (1988). Disproportionate epicardial dilation after transmural infarction of the canine left ventricle: acute and chronic differences. J. Am. College Cardiol. 11, 177-185. doi: 10.1016/0735-1097(88)90186-6

Kennedy, G., Meyer, D., Hardman, R. J., Macpherson, H., Scholey, A. B., and Pipingas, A. (2020). Modelling modifiable predictors of age-related cognitive decline: exercise, aortic stiffness, and the importance of physical fitness. J. Alzheimers Dis. Rep. 4, 79-89. doi: 10.3233/adr- 190164

Kennelly, S. P., Lawlor, B. A., and Kenny, R. A. (2009). Blood pressure and the risk for dementia-A double edged sword. Ageing Res. Rev. 8, 61-70. doi: 10.1016/j.arr.2008.11.001

Khalsa, D. S. (2015). Stress, meditation, and Alzheimer's disease prevention: where the evidence stands. J. Alzheimers Dis. 48, 1-12. doi: 10.3233/jad- 142766

Khan, M., Dhammu, T. S., Qiao, F., Kumar, P., Singh, A. K., and Singh, I. (2019). S-Nitrosoglutathione mimics the beneficial activity of endothelial nitric oxide synthase-derived nitric oxide in a mouse model of stroke. J. Stroke Cerebrovasc. Dis. 28:104470. doi: 10.1016/j.jstrokecerebrovasdis.2019.104470

Khan, S. J., Pham, S., Wei, Y., Mateo, D., St-Pierre, M., Fletcher, T. M., et al. (2010). Stress-induced senescence exaggerates postinjury neointimal formation in the old vasculature. Am. J. Physiol. Heart Circ. Physiol. 298, H66-H74.

Khawar, M. B., Gao, H., and Li, W. (2019). Autophagy and lipid metabolism. Adv. Exp. Med. Biol. 1206, 359-374.

Khoshdel, A. R., and Eshtiaghi, R. (2019). Assessment of arterial stiffness in metabolic syndrome related to insulin resistance in apparently healthy men. Metab. Syndr. Relat. Disord. 17, 90-96. doi: 10.1089/met.2018.0090

Kivipelto, M., Helkala, E. L., Laakso, M. P., Hänninen, T., Hallikainen, M., Alhainen, K., et al. (2001). Midlife vascular risk factors and Alzheimer's disease in later life: longitudinal, population based study. BMJ 322, 1447-1451. doi: 10.1136/bmj.322.7300.1447

Knight, E. M., Verkhratsky, A., Luckman, S. M., Allan, S. M., and Lawrence, C. B. (2012). Hypermetabolism in a triple-transgenic mouse model of Alzheimer's disease. Neurobiol. Aging 33, 187-193. doi: 10.1016/j.neurobiolaging.2010. 02.003

Ko, A. R., Kim, J. Y., Hyun, H. W., and Kim, J. E. (2015). Endothelial NOS activation induces the blood-brain barrier disruption via ER stress following status epilepticus. Brain Res. 1622, 163-173. doi: 10.1016/j.brainres.2015.06.020

Konior, A., Schramm, A., Czesnikiewicz-Guzik, M., and Guzik, T. J. (2014). NADPH oxidases in vascular pathology. Antioxid. Redox Signal. 20, 2794-2814. doi: $10.1089 /$ ars.2013.5607
Konoplyannikov, M., and Nurminskaya, M. (2014). New therapeutic approaches to arterial calcification via inhibition of transglutaminase and beta-catenin signaling. Curr. Pharm. Des. 20, 5811-5820. doi: $10.2174 / 1381612820666140212205059$

Kreutzberg, G. W. (1996). Microglia: a sensor for pathological events in the CNS. Trends Neurosci. 19, 312-318. doi: 10.1016/0166-2236(96)10049-7

Kumar, V. V., Huang, H., Zhao, L., Verble, D. D., Nutaitis, A., Tharwani, S. D. et al. (2020). Baseline results: the association between cardiovascular risk and preclinical Alzheimer's disease pathology (ASCEND) study. J. Alzheimers Dis. 75, 109-117. doi: 10.3233/jad- 191103

Lakatta, E. G. (2013). The reality of aging viewed from the arterial wall. Artery Res. 7, 73-80. doi: 10.1016/j.artres.2013.01.003

Lakatta, E. G., and Lévy, D. (2003). Arterial and cardiac aging: major shareholders in cardiovascular disease enterprises: Part I: aging arteries: a "set up" for vascular disease. Circulation 107, 139-146. doi: 10.1161/01.cir.0000048892. 83521.58

LaRocca, T., Gioscia-Ryan, R., Hearon, C. M., and Seals, D. (2013). The autophagy enhancer spermidine reverses arterial aging. Mech. Ageing Dev. 134, 314-320. doi: 10.1016/j.mad.2013.04.004

LaRocca, T. J., Henson, G. D., Thorburn, A., Sindler, A. L., Pierce, G. L., and Seals, D. R. (2012). Translational evidence that impaired autophagy contributes to arterial ageing. J. Physiol. 590, 3305-3316. doi: 10.1113/jphysiol.2012.229690

LaRocca, T. J., Martens, C. R., and Seals, D. R. (2017). Nutrition and other lifestyle influences on arterial aging. Ageing Res. Rev. 39, 106-119. doi: 10.1016/j.arr. 2016.09.002

Lattanzi, S., Cagnetti, C., Provinciali, L., and Silvestrini, M. (2015). Blood Pressure Variability and Clinical Outcome in Patients with Acute Intracerebral Hemorrhage. J. Stroke Cerebrovasc. Dis. 24, 1493-1499. doi: 10.1016/j. jstrokecerebrovasdis.2015.03.014

Lattanzi, S., Viticchi, G., Falsetti, L., Buratti, L., Luzzi, S., Provinciali, L., et al. (2014). Visit-to-visit blood pressure variability in Alzheimer disease. Alzheimer Dis. Assoc. Disord. 28:351.

Learoyd, B. M., and Taylor, M. (1966). Alterations with age in the viscoelastic properties of human arterial walls. Circ. Res. 18:292.

Lee, J. H., Palaia, T., and Ragolia, L. (2009). Impaired insulin-mediated vasorelaxation in diabetic Goto-Kakizaki rats is caused by impaired Akt phosphorylation. Am. J. Physiol. Cell Physiol. 296, C327-C338.

Lee, J. H., Palaia, T., and Ragolia, L. (2012). Impaired insulin-stimulated myosin phosphatase Rho-interacting protein signaling in diabetic Goto-Kakizaki vascular smooth muscle cells. Am. J. Physiol. Cell Physiol. 302, C1371-C1381.

Leloup, A. J., Fransen, P., Van Hove, C. E., Demolder, M., De Keulenaer, G. W., and Schrijvers, D. M. (2014). Applanation tonometry in mice: a novel noninvasive technique to assess pulse wave velocity and arterial stiffness. Hypertension 64, 195-200. doi: 10.1161/hypertensionaha.114.03312

Leloup, A. J. A., De Moudt, S., Van Hove, C. E., Dugaucquier, L., Vermeulen, Z., Segers, V. F. M., et al. (2018). Short-term angiotensin ii treatment affects large artery biomechanics and function in the absence of small artery alterations in mice. Front. Physiol. 9:582. doi: 10.3389/fphys.2018.00582

Leszek, J., Trypka, E., Tarasov, V. V., Ashraf, G. M., and Aliev, G. (2017). Type 3 diabetes mellitus: a novel implication of Alzheimers disease. Curr. Top. Med. Chem. 17, 1331-1335. doi: 10.2174/1568026617666170103163403

Li, S., Wang, Y., Jiang, Z., Huai, Y., Liao, J. K., Lynch, K. A., et al. (2018). Impaired cognitive performance in endothelial nitric oxide synthase knockout mice after ischemic stroke, a pilot study. Am. J. Phys. Med. Rehabil. 97:492. doi: $10.1097 / \mathrm{phm} .0000000000000904$

Li, X., Wang, H.-F., Li, X.-X., and Xu, M. (2019). Contribution of acid sphingomyelinase to angiotensin II-induced vascular adventitial remodeling via membrane rafts/Nox2 signal pathway. Life Sci. 219, 303-310. doi: 10.1016/j.lfs. 2019.01.028

Ling, L., Chen, D., Tong, Y., Zang, Y.-H., Ren, X.-S., Zhou, H., et al. (2018). Fibronectin type III domain containing 5 attenuates NLRP3 inflammasome activation and phenotypic transformation of adventitial fibroblasts in spontaneously hypertensive rats. J. Hypertens. 36, 1104-1114. doi: 10.1097/hjh. 0000000000001654

Liu, J., and Li, L. (2019). Targeting autophagy for the treatment of Alzheimer's disease: challenges and opportunities. Front. Mol. Neurosci. 12:203. doi: 10. 3389/fnmol.2019.00203 
Liu, Q. Y., Chang, M. N., Lei, J. X., Koukiekolo, R., Smith, B., Zhang, D., et al. (2014). Identification of microRNAs involved in Alzheimer's progression using a rabbit model of the disease. Am. J. Neurodegener. Dis. 3, 33-44.

London, G. M., and Pannier, B. (2010). Arterial functions: how to interpret the complex physiology. Nephrol. Dial. Transplant. 25, 3815-3823. doi: 10.1093/ ndt/gfq614

Lorentzen, K. A., Chai, S., Chen, H., Danielsen, C. C., Simonsen, U., and Wogensen, L. (2016). Mechanisms involved in extracellular matrix remodeling and arterial stiffness induced by hyaluronan accumulation. Atherosclerosis 244, 195-203. doi: 10.1016/j.atherosclerosis.2015.11.016

Louveau, A., Harris, T. H., and Kipnis, J. (2015). Revisiting the mechanisms of CNS immune privilege. Trends Immunol. 36, 569-577. doi: 10.1016/j.it.2015.08.006

Love, S., Chalmers, K., Ince, P., Esiri, M., Attems, J., Kalaria, R., et al. (2015). Development, appraisal, validation and implementation of a consensus protocol for the assessment of cerebral amyloid angiopathy in post-mortem brain tissue. Am. J. Neurodegen. Dis. 4:49.

Ma, R., Zhou, G., Qu, M., Yi, J.-H., Tang, Y., Yang, X.-y, et al. (2019). Corticosterone induces neurotoxicity in PC12 cells via disrupting autophagy flux mediated by AMPK/mTOR signaling. CNS Neurosci. Therap. 26, 167-176. doi: 10.1111/cns. 13212

Mahmud, A., and Feely, J. (2005). Arterial stiffness is related to systemic inflammation in essential hypertension. Hypertension 46, 1118-1122. doi: 10 . 1161/01.hyp.0000185463.27209.b0

Maki-Petaja, K., Chan, K., McEniery, C., and Wilkinson, I. (2016). 14.7 Hyaluronan is associated with aortic stiffening in healthy subjects. Artery Res. 16, 84-84. doi: 10.1016/j.artres.2016.10.127

Maki-Petaja, K., Patel, R., Cleary, S., Yasmin, M., and Wilkinson, I. (2012). P3. 05 the role of hyaluronan in aortic stiffening in patients with rheumatoid arthritis. Artery Res. 6, 178-178. doi: 10.1016/j.artres.2012.09.132

Malkov, A., Popova, I., Ivanov, A., Jang, S.-S., Yoon, S. Y., Osypov, A., et al. (2020). A $\beta$-induced NOX2 activation underlies oxidative stress leading to brain hypometabolism and hyperactivity in Alzheimer's disease. bioRxiv [Preprint] doi: 10.1101/2020.08.12.248492

Markus, M. R. P., Rospleszcz, S., Ittermann, T., Baumeister, S. E., Schipf, S., SiewertMarkus, U., et al. (2019). Glucose and insulin levels are associated with arterial stiffness and concentric remodeling of the heart. Cardiovasc. Diabetol. 18:145.

Mason, J. R., Tenenbaum, G., Jaime, S., Roque, N., Maharaj, A., and Figueroa, A. (2020). Arterial stiffness and cardiorespiratory fitness are associated with cognitive function in older adults. Behav. Med. doi: 10.1080/08964289.2020. 1825921 [Epub ahead of print].

Matsumoto, M., Inoue, K., and Moriki, A. (2007). Associations of brachial-ankle pulse wave velocity and carotid atherosclerotic lesions with silent cerebral lesions. Hypertens. Res. 30, 767-773. doi: 10.1291/hypres.30.767

Matsuzawa-Ishimoto, Y., Hwang, S., and Cadwell, K. (2018). Autophagy and inflammation. Annu. Rev. Immunol. 36, 73-101.

Maurer, K., Volk, S., and Gerbaldo, H. (1997). Auguste D and Alzheimer's disease. Lancet 349, 1546-1549.

Mayhan, W. G., Scott, J. P., and Arrick, D. M. (2015). Influence of type 1 diabetes on basal and agonist-induced permeability of the blood-brain barrier. Physiol. Rep. 3:e12653. doi: 10.14814/phy2.12653

Mayne, K., White, J. A., McMurran, C. E., Rivera, F. J., and de la Fuente, A. G. (2020). Aging and neurodegenerative disease: is the adaptive immune system a friend or foe? Front. Aging Neurosci. 12:572090. doi: 10.3389/fnagi.2020. 572090

McCarthy, C. G., Wenceslau, C. F., Calmasini, F. B., Klee, N. S., Brands, M. W., Joe, B., et al. (2019). Reconstitution of autophagy ameliorates vascular function and arterial stiffening in spontaneously hypertensive rats. Am. J. Physiol. Heart Circ. Physiol. 317, H1013-H1027.

McKhann, G. M., Knopman, D. S., Chertkow, H., Hyman, B. T., Jack, C. R. Jr., Kawas, C. H., et al. (2011). The diagnosis of dementia due to Alzheimer's disease: recommendations from the National Institute on Aging-Alzheimer's Association workgroups on diagnostic guidelines for Alzheimer's disease. Alzheimers Dement. 7, 263-269.

Medeiros, R., and LaFerla, F. M. (2013). Astrocytes: conductors of the Alzheimer disease neuroinflammatory symphony. Exp. Neurol. 239, 133-138. doi: 10 . 1016/j.expneurol.2012.10.007

Medzhitov, R. (2008). Origin and physiological roles of inflammation. Nature 454, 428-435. doi: 10.1038/nature07201
Mega, M. S., Cummings, J. L., Fiorello, T., and Gornbein, J. (1996). The spectrum of behavioral changes in Alzheimer's disease. Neurology 46, 130-135.

Mergenthaler, P., Lindauer, U., Dienel, G. A., and Meisel, A. (2013). Sugar for the brain: the role of glucose in physiological and pathological brain function. Trends Neurosci. 36, 587-597. doi: 10.1016/j.tins.2013.07.001

Merlini, M., Kirabali, T., Kulic, L., Nitsch, R. M., and Ferretti, M. T. (2018). Extravascular CD3 + T cells in brains of Alzheimer disease patients correlate with tau but not with amyloid pathology: an immunohistochemical study. Neurodegener. Dis. 18, 49-56. doi: 10.1159/000486200

Meyer, M. L., Palta, P., Tanaka, H., Deal, J. A., Wright, J., Knopman, D. S., et al. (2017). Association of central arterial stiffness and pressure pulsatility with mild cognitive impairment and dementia: the Atherosclerosis Risk in Communities Study-Neurocognitive Study (ARIC-NCS). J. Alzheimers Dis. 57, 195-204. doi: 10.3233/jad-161041

Michiels, C. F., Fransen, P., De Munck, D. G., De Meyer, G. R. Y., and Martinet, W. (2015). Defective autophagy in vascular smooth muscle cells alters contractility and $\mathrm{Ca}(2)(+)$ homeostasis in mice. Am. J. Physiol. Heart Circ. Physiol. 308, H557-H567.

Migrino, R. Q., Davies, H. A., Truran, S., Karamanova, N., Franco, D. A., Beach, T. G., et al. (2017). Amyloidogenic medin induces endothelial dysfunction and vascular inflammation through the receptor for advanced glycation endproducts. Cardiovasc. Res. 113, 1389-1402. doi: 10.1093/cvr/ cvx135

Migrino, R. Q., Karamanova, N., Truran, S., Serrano, G. E., Davies, H. A., Madine, J., et al. (2020). Cerebrovascular medin is associated with Alzheimer's disease and vascular dementia. Alzheimers Dement. (Amst.) 12:e12072.

Miller, T. W., Isenberg, J. S., Shih, H. B., Wang, Y., and Roberts, D. D. (2010). Amyloid- $\beta$ inhibits No-cGMP signaling in a CD36-and CD47-dependent manner. PLoS One 5:e15686. doi: 10.1371/journal.pone.0015686

Minor, R. W. (1982). Hemodynamics. Philadelphia, PA: Williams and Wilkins.

Miquel, J. (2009). An update of the oxidation-inflammation theory of aging: the involvement of the immune system in oxi-inflamm-aging. Curr. Pharm. Des. 15, 3003-3026. doi: 10.2174/138161209789058110

Mitchell, G. F., van Buchem, M. A., Sigurdsson, S., Gotal, J. D., Jonsdottir, M. K., Kjartansson, Ó, et al. (2011). Arterial stiffness, pressure and flow pulsatility and brain structure and function: the Age, Gene/Environment SusceptibilityReykjavik study. Brain 134, 3398-3407. doi: 10.1093/brain/awr253

Molitor, M., Rudi, W.-S., Garlapati, V., Finger, S., Schüler, R., Kossmann, S., et al. (2021). Nox2+ myeloid cells drive vascular inflammation and endothelial dysfunction in heart failure after myocardial infarction via angiotensin II receptor type 1. Cardiovasc. Res. 117, 162-177. doi: 10.1093/cvr/cvaa042

Montine, T. J., Phelps, C. H., Beach, T. G., Bigio, E. H., Cairns, N. J., Dickson, D. W., et al. (2012). National institute on aging-Alzheimer's association guidelines for the neuropathologic assessment of Alzheimer's disease: a practical approach. Acta Neuropathol. 123, 1-11.

Moon, S. W., Byun, M. S., Yi, D., Lee, J. H., Jeon, S. Y., Lee, Y., et al. (2019). The Ankle-Brachial index is associated with cerebral $\beta$-amyloid deposition in cognitively normal older adults. J. Gerontol. Ser. A 74, 1141-1148. doi: $10.1093 /$ gerona/gly157

Morris, B. J., Willcox, B. J., and Donlon, T. A. (2019). Genetic and epigenetic regulation of human aging and longevity. Biochim. Biophys. Acta Mol. Basis Dis. 1865, 1718-1744. doi: 10.1016/j.bbadis.2018.08.039

Mozos, I., and Luca, C. T. (2017). Crosstalk between oxidative and nitrosative stress and arterial stiffness. Curr. Vasc. Pharmacol. 15, 446-456.

Muhire, G., Iulita, M. F., Vallerand, D., Youwakim, J., Gratuze, M., Petry, F. R., et al. (2019). Arterial stiffness due to carotid calcification disrupts cerebral blood flow regulation and leads to cognitive deficits. J. Am. Heart Assoc. 8:e011630.

Muller, M., Grobbee, D., Aleman, A., Bots, M., and Van der Schouw, Y. (2007). Cardiovascular disease and cognitive performance in middle-aged and elderly men. Atherosclerosis 190, 143-149. doi: 10.1016/j.atherosclerosis.2006.01.005

Munji, R. N., Soung, A. L., Weiner, G. A., Sohet, F., Semple, B. D., Trivedi, A., et al. (2019). Profiling the mouse brain endothelial transcriptome in health and disease models reveals a core blood-brain barrier dysfunction module. Nat. Neurosci. 22, 1892-1902. doi: 10.1038/s41593-019-0497-x

Nagy, Z., Esiri, M., Jobst, K., Morris, J., King, E.-F., McDonald, B., et al. (1995). Relative roles of plaques and tangles in the dementia of Alzheimer's disease: correlations using three sets of neuropathological criteria. Dement. Geriatr. Cogn. Disord. 6, 21-31. doi: 10.1159/000106918 
Namba, T., Masaki, N., Takase, B., and Adachi, T. (2019). Arterial stiffness assessed by cardio-ankle vascular index. Int. J. Mol. Sci. 20:3664. doi: 10.3390/ ijms 20153664

Nascimento, A., Barros, D., Oliveira, J., Carvalho, J., and Bohn, L. (2019). Physical fitness is a mediator in the relationship between arterial stiffness and cognitive function. Artery Res. 25, 151-155.

Neuner, S. M., Heuer, S. E., Huentelman, M. J., O'Connell, K. M. S., and Kaczorowski, C. C. (2019). Harnessing genetic complexity to enhance translatability of Alzheimer's disease mouse models: a path toward precision medicine. Neuron 101, 399-411.e5.

Neutel, C. H. G., Hendrickx, J. O., Martinet, W., De Meyer, G. R. Y., and Guns, P. J. (2020). The protective effects of the autophagic and lysosomal machinery in vascular and valvular calcification: a systematic review. Int. J. Mol. Sci. 21:8933. doi: $10.3390 /$ ijms 21238933

Nimmerjahn, A., Kirchhoff, F., and Helmchen, F. (2005). Resting microglial cells are highly dynamic surveillants of brain parenchyma in vivo. Science 308, 1314-1318. doi: 10.1126/science.1110647

Noguchi-Shinohara, M., Komatsu, J., Samuraki, M., Matsunari, I., Ikeda, T., Sakai, K., et al. (2017). Cerebral amyloid angiopathy-related microbleeds and cerebrospinal fluid biomarkers in Alzheimer's disease. J. Alzheimers Dis. 55, 905-913. doi: 10.3233/jad-160651

Noordergraaf, A., Li, J., and Campbell, K. B. (1979). Mammalian hemodynamics: a new similarity principle. J. Theor. Biol. 79, 485-489. doi: 10.1016/00225193(79)90239-x

Norden, D. M., and Godbout, J. P. (2013). Microglia of the aged brain: primed to be activated and resistant to regulation. Neuropathol. Appl. Neurobiol. 39, 19-34. doi: 10.1111/j.1365-2990.2012.01306.x

Nunan, J., and Small, D. H. (2000). Regulation of APP cleavage by $\alpha$-, $\beta$-and $\gamma$-secretases. FEBS Lett. 483, 6-10. doi: 10.1016/s0014-5793(00)02076-7

Oberstein, T. J., Taha, L., Spitzer, P., Hellstern, J., Herrmann, M., Kornhuber, J., et al. (2018). Imbalance of circulating Th17 and regulatory T cells in Alzheimer's disease: a case control study. Front. Immunol. 9:1213. doi: 10.3389/fimmu.2018. 01213

Olver, T. D., Grunewald, Z. I., Ghiarone, T., Restaino, R. M., Sales, A. R. K., Park, L. K., et al. (2019). Persistent insulin signaling coupled with restricted PI3K activation causes insulin-induced vasoconstriction. Am. J. Physiol. Heart Circ. Physiol. 317, H1166-H1172.

Orgeta, V., Qazi, A., Spector, A., and Orrell, M. (2015). Psychological treatments for depression and anxiety in dementia and mild cognitive impairment: systematic review and meta-analysis. Br. J. Psychiatry 207, 293-298. doi: 10.1192/bjp.bp. 114.148130

Ormazabal, V., Nair, S., Elfeky, O., Aguayo, C., Salomon, C., and Zuniga, F. A. (2018). Association between insulin resistance and the development of cardiovascular disease. Cardiovasc. Diabetol. 17:122.

O'Rourke, M., O’Brien, C. C., and Weber, T. (2014). “Arterial stiffness, wave reflection, wave amplification: basic concepts, principles of measurement and analysis in humans," in Blood Pressure and Arterial Wall Mechanics in Cardiovascular Diseases, eds M. Safar, M. O’Rourke, and E. Frohlich (London: Springer).

O'Rourke, M. F., and Hashimoto, J. (2007). Mechanical factors in arterial aging: a clinical perspective. J. Am. Coll. Cardiol. 50, 1-13. doi: 10.1016/j.jacc.2006.12. 050

O'Rourke, M. F., and Safar, M. E. (2005). Relationship between aortic stiffening and microvascular disease in brain and kidney: cause and logic of therapy. Hypertension 46, 200-204. doi: 10.1161/01.hyp.0000168052. 00426.65

Ouseph, M. M., Huang, Y., Banerjee, M., Joshi, S., MacDonald, L., Zhong, Y., et al. (2015). Autophagy is induced upon platelet activation and is essential for hemostasis and thrombosis. Blood 126, 1224-1233. doi: 10.1182/blood-201409-598722

Padilla, J., Vieira-Potter, V. J., Jia, G., and Sowers, J. R. (2015). Role of perivascular adipose tissue on vascular reactive oxygen species in type 2 diabetes: a give-andtake relationship. Diabetes 64, 1904-1906. doi: 10.2337/db15-0096

Paglini, G., Peris, L., Mascotti, F., Quiroga, S., and Caceres, A. (2000). Tau protein function in axonal formation. Neurochem. Res. 25, 37-42.

Panday, A., Sahoo, M. K., Osorio, D., and Batra, S. (2015). NADPH oxidases: an overview from structure to innate immunity-associated pathologies. Cell. Mol. Immunol. 12, 5-23. doi: 10.1038/cmi.2014.89
Paouri, E., and Georgopoulos, S. (2019). Systemic and CNS inflammation crosstalk: implications for Alzheimer's disease. Curr. Alzheimer Res. 16, 559-574. doi: $10.2174 / 1567205016666190321154618$

Park, S., and Lakatta, E. G. (2012). Role of inflammation in the pathogenesis of arterial stiffness. Yonsei Med. J. 53, 258-261. doi: 10.3349/ymj.2012.53.2.258

Pase, M. P., Himali, J. J., Mitchell, G. F., Beiser, A., Maillard, P., Tsao, C., et al. (2016). Association of aortic stiffness with cognition and brain aging in young and middle-aged adults: the Framingham Third Generation Cohort study. Hypertension 67, 513-519. doi: 10.1161/hypertensionaha.115.06610

Pasha, E. P., Rutjes, E., Tomoto, T., Tarumi, T., Stowe, A., Claassen, J., et al. (2020). Carotid stiffness is associated with brain amyloid-beta burden in amnestic mild cognitive impairment. J. Alzheimers Dis. 74, 925-935. doi: 10.3233/jad- 191073

Pegueroles, J., Pane, A., Montal, V., Vilaplana, E., Blesa, R., Lleó, A., et al. (2019). P2-347: overlap pattern of hypermetabolism and brain atrophy related with obesity in healthy elderly. Alzheimers Dement. 15, 728-729.

Pereira, T., Cipriano, I., Costa, T., Saraiva, M., and Martins, A. (2019). Effects of a personalized physical exercise program in the arterial stiffness and cognitive function in older adults-the Aga@ 4LIFE intervention model. J. Hypertens. 37, e236-e237.

Pérez-Torres, I., Manzano-Pech, L., Rubio-Ruíz, M. E., Soto, M. E., and GuarnerLans, V. (2020). Nitrosative stress and its association with cardiometabolic disorders. Molecules 25:2555. doi: 10.3390/molecules25112555

Petrov, D., Pedros, I., Artiach, G., Sureda, F. X., Barroso, E., Pallas, M., et al. (2015). High-fat diet-induced deregulation of hippocampal insulin signaling and mitochondrial homeostasis deficiences contribute to Alzheimer disease pathology in rodents. Biochim. Biophys. Acta 1852, 1687-1699. doi: 10.1016/ j.bbadis.2015.05.004

Peyster, E., Chen, J., Feldman, H. I., Go, A. S., Gupta, J., Mitra, N., et al. (2017). Inflammation and arterial stiffness in chronic kidney disease: findings from the CRIC study. Am. J. Hypertens. 30, 400-408. doi: 10.1093/ajh/hpw164

Poels, M. M., Zaccai, K., Verwoert, G. C., Vernooij, M. W., Hofman, A., van der Lugt, A., et al. (2012). Arterial stiffness and cerebral small vessel disease: the Rotterdam scan study. Stroke 43, 2637-2642. doi: 10.1161/strokeaha.111. 642264

Prelli, F., Castano, E., Glenner, G. G., and Frangione, B. (1988). Differences between vascular and plaque core amyloid in Alzheimer's disease. J. Neurochem. 51, 648-651. doi: 10.1111/j.1471-4159.1988.tb01087.x

Protogerou, A. D., Blacher, J., Stergiou, G. S., Achimastos, A., and Safar, M. E. (2009). Blood pressure response under chronic antihypertensive drug therapy: the role of aortic stiffness in the REASON (Preterax in Regression of Arterial Stiffness in a Controlled Double-Blind) study. J. Am. Coll. Cardiol. 53, 445-451.

Pugazhenthi, S., Qin, L., and Reddy, P. H. (2017). Common neurodegenerative pathways in obesity, diabetes, and Alzheimer's disease. Biochim. Biophys. Acta Mol. Basis Dis. 1863, 1037-1045. doi: 10.1016/j.bbadis.2016.04.017

Qosa, H., and Kaddoumi, A. (2016). Effect of mouse strain as a background for Alzheimer's disease models on the clearance of amyloid- $\beta$. J. Syst. Integr. Neurosci. 2:135. doi: 10.15761/jsin.1000123

Rabkin, S. W. (2012). Arterial stiffness: detection and consequences in cognitive impairment and dementia of the elderly. J. Alzheimers Dis. 32, 541-549. doi: 10.3233/jad-2012-120757

Riazi, K., Galic, M. A., Kentner, A. C., Reid, A. Y., Sharkey, K. A., and Pittman, Q. J. (2015). Microglia-dependent alteration of glutamatergic synaptic transmission and plasticity in the hippocampus during peripheral inflammation. J. Neurosci. 35, 4942-4952. doi: 10.1523/jneurosci.4485-14.2015

Rivera-Rivera, L. A., Cody, K. A., Eisenmenger, L., Cary, P., Rowley, H. A., Carlsson, C. M., et al. (2020). Assessment of vascular stiffness in the internal carotid artery proximal to the carotid canal in Alzheimer's disease using pulse wave velocity from low rank reconstructed 4D flow MRI. J. Cereb. Blood Flow Metab. 41, 298-311. doi: 10.1177/0271678X20910302 doi: 10.1177/ 0271678x20910302

Rodrigue, K. M., Rieck, J. R., Kennedy, K. M., Devous, M. D., Diaz-Arrastia, R., and Park, D. C. (2013). Risk factors for $\beta$-amyloid deposition in healthy aging: vascular and genetic effects. JAMA Neurol. 70, 600-606. doi: 10.1001/ jamaneurol.2013.1342

Rogers, J., Luber-Narod, J., Styren, S. D., and Civin, W. H. (1988). Expression of immune system-associated antigens by cells of the human central nervous system: relationship to the pathology of Alzheimer's disease. Neurobiol. Aging 9, 339-349. doi: 10.1016/s0197-4580(88)80079-4 
Safar, M., and London, G. (1987). Arterial and venous compliance in sustained essential hypertension. Hypertension 10, 133-139. doi: 10.1161/01.hyp.10.2.133

Safar, M. E., Lévy, B. I., and Struijker-Boudier, H. A. J. (2003). Current perspectives on arterial stiffness and pulse pressure in hypertension and cardiovascular diseases. Circulation 107, 2864-2869. doi: 10.1161/01.cir.0000069826.36125.b4

Said, M. A., Eppinga, R. N., Lipsic, E., Verweij, N., and van der Harst, P. (2018). Relationship of arterial stiffness index and pulse pressure with cardiovascular disease and mortality. J. Am. Heart Assoc. 7:e007621.

Sallam, H. S., Tumurbaatar, B., Zhang, W. R., Tuvdendorj, D., Chandalia, M., Tempia, F., et al. (2015). Peripheral adipose tissue insulin resistance alters lipid composition and function of hippocampal synapses. J. Neurochem. 133, 125-133. doi: 10.1111/jnc. 13043

Salminen, A., Kaarniranta, K., and Kauppinen, A. (2012). Inflammaging: disturbed interplay between autophagy and inflammasomes. Aging (Albany NY) 4:166. doi: 10.18632/aging.100444

Sampath Kumar, A., Maiya, A. G., Shastry, B. A., Vaishali, K., Ravishankar, N., Hazari, A., et al. (2019). Exercise and insulin resistance in type 2 diabetes mellitus: a systematic review and meta-analysis. Ann. Phys. Rehabil. Med. 62, 98-103.

Sankowski, R., Mader, S., and Valdes-Ferrer, S. I. (2015). Systemic inflammation and the brain: novel roles of genetic, molecular, and environmental cues as drivers of neurodegeneration. Front. Cell Neurosci. 9:28. doi: 10.3389/fncel. 2015.00028

Sarkate, A. P., Lokwani, D. K., Karnik, K. S., and Shinde, D. B. (2017). Novel 2-(nitrooxy)ethyl 2-(4-(substituted phenyl)-2-((substituted phenyl)amino)thiazol-5-yl)acetate as anti-inflammatory, analgesic and nitric oxide releasing agents: synthesis and molecular docking studies. Antiinflamm. Antiallergy Agents Med. Chem. 16, 153-167.

Sena, C. M., Pereira, A. M., and Seiça, R. (2013). Endothelial dysfunction-a major mediator of diabetic vascular disease. Biochim. Biophys. Acta Mol. Basis Dis. $1832,2216-2231$.

Seo, H. S., Kang, T. S., Park, S., Park, H. Y., Ko, Y. G., Choi, D., et al. (2005). Insulin resistance is associated with arterial stiffness in nondiabetic hypertensives independent of metabolic status. Hypertens. Res. 28, 945-951.

Serrano-Pozo, A., Frosch, M. P., Masliah, E., and Hyman, B. T. (2011). Neuropathological alterations in Alzheimer disease. Cold Spring Harb. Perspect. Med. 1:a006189.

Sharma, J. N., Al-Omran, A., and Parvathy, S. S. (2007). Role of nitric oxide in inflammatory diseases. Inflammopharmacology 15, 252-259.

Sherikar, A., Dhavale, R., and Bhatia, M. (2019). Investigation of antiinflammatory, nitric oxide donating, vasorelaxation and ulcerogenic activities of 1, 3-diphenylprop-2-en-1-one derivatives in animal models. Clin. Exp. Pharmacol. Physiol. 46, 483-495.

Simpson, D. S., and Oliver, P. L. (2020). ROS generation in microglia: Understanding oxidative stress and inflammation in neurodegenerative disease. Antioxidants 9:743.

Sindler, A. L., Fleenor, B. S., Calvert, J. W., Marshall, K. D., Zigler, M. L., Lefer, D. J., et al. (2011). Nitrite supplementation reverses vascular endothelial dysfunction and large elastic artery stiffness with aging. Aging Cell 10, 429-437.

Skaper, S. D., Facci, L., Zusso, M., and Giusti, P. (2018). An inflammation-centric view of neurological disease: beyond the neuron. Front. Cell. Neurosci. 12:72. doi: 10.3389/fncel.2018.00072

Skoog, I., Nilsson, L., Persson, G., Lernfelt, B., and Svanborg, A. (1996). 15-year longitudinal study of blood pressure and dementia. Lancet 347, 1141-1145.

Smirnov, D. S., Bangen, K. J., Galasko, D. R., Brewer, J. B., and Salmon, D. P. (2020). Arterial stiffness acts synergistically with APOE genotype and amyloid status to predict cognitive impairment in non-demented elderly: Neuropsychology/Neuropsychological profiles of dementia: valid biomarkers? Alzheimers Dement. 16:e46460.

Soares, E. S., Mendonca, M. C., and da Cruz-Hofling, M. A. (2015). eNOS uncoupling in the cerebellum after BBB disruption by exposure to Phoneutria nigriventer spider venom. Toxicon 104, 7-13.

Spinetti, G., Wang, M., Monticone, R., Zhang, J., Zhao, D., and Lakatta, E. G. (2004). Rat aortic MCP-1 and its receptor CCR2 increase with age and alter vascular smooth muscle cell function. Arterioscler. Thromb. Vasc. Biol. 24, 1397-1402.

Stakos, D. A., Stamatelopoulos, K., Bampatsias, D., Sachse, M., Zormpas, E., Vlachogiannis, N. I., et al. (2020). The Alzheimer's disease amyloid-beta hypothesis in cardiovascular aging and disease: JACC focus seminar. J. Am. Coll. Cardiol. 75, 952-967.

Stamatelopoulos, K., Pol, C. J., Ayers, C., Georgiopoulos, G., Gatsiou, A., Brilakis, E. S., et al. (2018). Amyloid-Beta (1-40) peptide and subclinical cardiovascular disease. J. Am. Coll. Cardiol. 72, 1060-1061.

Stamatelopoulos, K., Sibbing, D., Rallidis, L. S., Georgiopoulos, G., Stakos, D., Braun, S., et al. (2015). Amyloid-beta (1-40) and the risk of death from cardiovascular causes in patients with coronary heart disease. J. Am. Coll. Cardiol. 65, 904-916.

Starr, L. R., Dienes, K., Li, Y. I., and Shaw, Z. A. (2019). Chronic stress exposure, diurnal cortisol slope, and implications for mood and fatigue: moderation by multilocus HPA-Axis genetic variation. Psychoneuroendocrinology 100, 156-163.

Stefano, G. B., Esch, T., Ptacek, R., and Kream, R. M. (2020). Dysregulation of nitric oxide signaling in microglia: multiple points of functional convergence in the complex pathophysiology of Alzheimer disease. Med. Sci. Monit. 26:e927739.

Steppan, J., Tran, H., Benjo, A. M., Pellakuru, L., Barodka, V., Ryoo, S., et al. (2012). Alagebrium in combination with exercise ameliorates age-associated ventricular and vascular stiffness. Exp. Gerontol. 47, 565-572.

Suri, S., Chiesa, S. T., Zsoldos, E., Mackay, C. E., Filippini, N., Griffanti, L., et al. (2020). Associations between arterial stiffening and brain structure, perfusion, and cognition in the Whitehall II Imaging Sub-study: a retrospective cohort study. PLoS Med. 17:e1003467. doi: 10.1371/journal.pmed.1003467

Suzuki, N., Iwatsubo, T., Odaka, A., Ishibashi, Y., Kitada, C., and Ihara, Y. (1994). High tissue content of soluble beta 1-40 is linked to cerebral amyloid angiopathy. Am. J. Pathol. 145:452.

Sweeney, M. D., Zhao, Z., Montagne, A., Nelson, A. R., and Zlokovic, B. V. (2019). Blood-brain barrier: from physiology to disease and back. Physiol. Rev. 99, 21-78.

Tabatabaei, S. N., and Girouard, H. (2014). Nitric oxide and cerebrovascular regulation. Vitamins Horm. 96, 347-385.

Taheri, S., Gasparovic, C., Huisa, B. N., Adair, J. C., Edmonds, E., Prestopnik, J., et al. (2011). Blood-brain barrier permeability abnormalities in vascular cognitive impairment. Stroke 42, 2158-2163.

Takeda, S., Sato, N., Takeuchi, D., Kurinami, H., Shinohara, M., Niisato, K., et al. (2009). Angiotensin receptor blocker prevented \&bgr;-amyloid?Induced cognitive impairment associated with recovery of neurovascular coupling. Hypertension 54, 1345-1352.

Tan, X.-L., Xue, Y.-Q., Ma, T., Wang, X., Li, J. J., Lan, L., et al. (2015). Partial eNOS deficiency causes spontaneous thrombotic cerebral infarction, amyloid angiopathy and cognitive impairment. Mol. Neurodegener. 10, 1-14.

Tang, F., Chan, E., Lu, M., Zhang, X., Dai, C., Mei, M., et al. (2015). Calpain1 mediated disorder of pyrophosphate metabolism contributes to vascular calcification induced by oxLDL. PLoS One 10:e0129128. doi: 10.1371/journal. pone. 0129128

Tang, X., Li, Z., Zhang, W., and Yao, Z. (2019). Nitric oxide might be an inducing factor in cognitive impairment in Alzheimer's disease via downregulating the monocarboxylate transporter 1. Nitric Oxide 91, 35-41.

Tapp, Z. M., Godbout, J. P., and Kokiko-Cochran, O. N. (2019). A tilted axis: maladaptive inflammation and HPA axis dysfunction contribute to consequences of TBI. Front. Neurol. 10:345. doi: 10.3389/fneur.2019. 00345

Tariot, P. N., Mack, J. L., Patterson, M. B., Edland, S. D., Weiner, M. F., Fillenbaum, G., et al. (1995). The behavior rating scale for dementia of the Consortium to Establish a Registry for Alzheimer's Disease. Am. J. Psychiatry 152, 1349-1357.

Taverne, Y. J., de Beer, V. J., Hoogteijling, B. A., Juni, R. P., Moens, A. L., Duncker, D. J., et al. (2012). Nitroso-redox balance in control of coronary vasomotor tone. J. Appl. Physiol. 112, 1644-1652.

Thal, D. R., Rub, U., Orantes, M., and Braak, H. (2002). Phases of A beta-deposition in the human brain and its relevance for the development of AD. Neurology 58, 1791-1800.

Thanassoulis, G., Massaro, J. M., Corsini, E., Rogers, I., Schlett, C. L., Meigs, J. B., et al. (2012). Periaortic adipose tissue and aortic dimensions in the Framingham Heart Study. J. Am. Heart Assoc. 1:e000885.

Thoenes, M., Neuberger, H. R., Volpe, M., Khan, B. V., Kirch, W., and Böhm, M. (2010). Antihypertensive drug therapy and blood pressure control in men and women: an international perspective. J. Hum. Hypertens. 24, 336-344. 
Tijsseling, A. S., and Anderson, A. W. A. (2012). “Isebree Moens and D.J. Korteweg: on the speed of propagation of waves in elastic tubes," in Proceedings of the 11th International. Conference. on Pressure Surges (Lisbon: BHR Group), 227-245.

Togo, T., Akiyama, H., Iseki, E., Kondo, H., Ikeda, K., Kato, M., et al. (2002). Occurrence of T cells in the brain of Alzheimer's disease and other neurological diseases. J. Neuroimmunol. 124, 83-92.

Toral, M., Romero, M., Rodríguez-Nogales, A., Jiménez, R., Robles-Vera, I., Algieri, F., et al. (2018). Lactobacillus fermentum improves tacrolimus-induced hypertension by restoring vascular redox state and improving eNOS coupling. Mol. Nutr. Food Res. 62:1800033.

Tounian, P., Aggoun, Y., Dubern, B., Varille, V., Guy-Grand, B., Sidi, D., et al. (2001). Presence of increased stiffness of the common carotid artery and endothelial dysfunction in severely obese children: a prospective study. Lancet 358, 1400-1404.

Tsao, C. W., Seshadri, S., Beiser, A. S., Westwood, A. J., DeCarli, C., Au, R., et al. (2013). Relations of arterial stiffness and endothelial function to brain aging in the community. Neurology 81, 984-991.

Tulla, H., Takala, J., Alhava, E., Huttunen, H., and Kari, A. (1991). Hypermetabolism after coronary artery bypass. J. Thorac. Cardiovasc. Surg. 101, 598-600.

Vahia, V. N. (2013). Diagnostic and statistical manual of mental disorders 5: a quick glance. Indian J. Psychiatry 55:220.

van Sloten, T. T., Protogerou, A. D., Henry, R. M., Schram, M. T., Launer, L. J., and Stehouwer, C. D. (2015). Association between arterial stiffness, cerebral small vessel disease and cognitive impairment: a systematic review and meta-analysis. Neurosci. Biobehav. Rev. 53, 121-130.

Varadharaj, S., Reyes, L., Crestenello, J., Kilic, A., Talukder, H., Chen, C.-A., et al. (2012). Vascular eNOS S-glutathionylation is increased in hypertension and atherosclerosis with eNOS uncoupling: data from animal models and human aortic tissue of patients undergoing surgical revascularization. Circulation 126:A19796.

Vargas-Hitos, J. A., Soriano-Maldonado, A., Martinez-Bordonado, J., SanchezBerna, I., Fernandez-Berges, D., and Sabio, J. M. (2018). Association of resting heart rate with arterial stiffness and low-grade inflammation in women with systemic lupus erythematosus. Angiology 69, 672-676.

Veitinger, M., Varga, B., Guterres, S. B., and Zellner, M. (2014). Platelets, a reliable source for peripheral Alzheimer's disease biomarkers? Acta Neuropathol. Commun. 2, 1-15.

Verghese, P. B., Castellano, J. M., and Holtzman, D. M. (2011). Apolipoprotein $\mathrm{E}$ in Alzheimer's disease and other neurological disorders. Lancet Neurol. 10, 241-252.

Villacorta, L., and Chang, L. (2015). The role of perivascular adipose tissue in vasoconstriction, arterial stiffness, and aneurysm. Horm. Mol. Biol. Clin. Investig. $21,137-147$.

Visconte, C., Canino, J., Guidetti, G. F., Zara, M., Seppi, C., Abubaker, A. A., et al. (2018). Amyloid precursor protein is required for in vitro platelet adhesion to amyloid peptides and potentiation of thrombus formation. Cell. Signal. 52, 95-102.

Vlachopoulos, C., Aznaouridis, K., Dima, I., Ioakeimidis, N., Vasiliadou, C., Zervoudaki, A., et al. (2007). Negative association between serum levels of matrix metalloproteinases- 2 and -9 and aortic stiffness in healthy adults. Int. J. Cardiol. 122, 232-238.

Vlachopoulos, C., O'Rourke, M., and Nichols, W. W. (2011). McDonald's Blood Flow in Arteries: Theoretical, Experimental and Clinical Principles. Boca Raton, FL: CRC Press.

Vlachopoulos, C., Xaplanteris, P., Alexopoulos, N., Aznaouridis, K., Vasiliadou, C., Baou, K., et al. (2009). Divergent effects of laughter and mental stress on arterial stiffness and central hemodynamics. Psychosom. Med. 71, 446-453.

Vloeberghs, E., Van Dam, D., Franck, F., Serroyen, J., Geert, M., Staufenbiel, M., et al. (2008). Altered ingestive behavior, weight changes, and intact olfactory sense in an APP overexpression model. Behav. Neurosci. 122:491.

Wahl, D., Solon-Biet, S. M., Cogger, V. C., Fontana, L., Simpson, S. J., Le Couteur, D. G., et al. (2019). Aging, lifestyle and dementia. Neurobiol. Dis. 130:104481.

Walker, K. A., Ficek, B. N., and Westbrook, R. (2019). Understanding the role of systemic inflammation in Alzheimer's disease. ACS Chem. Neurosci. 10, 3340-3342.
Wang, M., Fu, Z., Wu, J., Zhang, J., Jiang, L., Khazan, B., et al. (2012). MFG-E8 activates proliferation of vascular smooth muscle cells via integrin signaling. Aging Cell 11, 500-508.

Wang, M., Jiang, L., Monticone, R. E., and Lakatta, E. G. (2014). Proinflammation: the key to arterial aging. Trends Endocrinol. Metab. 25, 72-79.

Wang, M., Wang, H. H., and Lakatta, E. G. (2013). Milk fat globule epidermal growth factor VIII signaling in arterial wall remodeling. Curr. Vasc. Pharmacol. $11,768-776$.

Wang, M., Zhao, D., Spinetti, G., Zhang, J., Jiang, L. Q., Pintus, G., et al. (2006). Matrix metalloproteinase 2 activation of transforming growth factor-beta1 (TGF-beta1) and TGF-beta1-type II receptor signaling within the aged arterial wall. Arterioscler. Thromb. Vasc. Biol. 26, 1503-1509.

Wardlaw, J. M., Doubal, F. N., Valdes-Hernandez, M., Wang, X., Chappell, F. M., Shuler, K., et al. (2013). Blood-brain barrier permeability and longterm clinical and imaging outcomes in cerebral small vessel disease. Stroke 44, 525-527.

Watson, N. L., Sutton-Tyrrell, K., Rosano, C., Boudreau, R. M., Hardy, S. E., Simonsick, E. M., et al. (2011). Arterial stiffness and cognitive decline in well-functioning older adults. J. Gerontol. Ser. A Biomed. Sci. Med. Sci. 66, 1336-1342.

Webers, A., Heneka, M. T., and Gleeson, P. A. (2020). The role of innate immune responses and neuroinflammation in amyloid accumulation and progression of Alzheimer's disease. Immunol. Cell Biol. 98, 28-41.

Weller, R. O., Massey, A., Newman, T. A., Hutchings, M., Kuo, Y.-M., and Roher, A. E. (1998). Cerebral amyloid angiopathy: amyloid $\beta$ accumulates in putative interstitial fluid drainage pathways in Alzheimer's disease. Am. J. Pathol. 153, $725-733$.

WHO (2017). Cardiovascular diseases (CVDs). Available online at: https://www. who.int/en/news-room/fact-sheets/detail/cardiovascular-diseases-(cvds). (accessed December 22, 2020)

WHO (2018). Report on Ageing and Health. Available online at: https://www. who.int/news-room/fact-sheets/detail/ageing-and-health (accessed December 12 2020)

Wilkins, H. M., Carl, S. M., Greenlief, A. C., Festoff, B. W., and Swerdlow, R. H. (2014). Bioenergetic dysfunction and inflammation in Alzheimer's disease: a possible connection. Front. Aging Neurosci. 6:311. doi: 10.3389/fnagi.2014. 00311

Willette, A. A., Modanlo, N., and Kapogiannis, D. (2015). Insulin resistance predicts medial temporal hypermetabolism in mild cognitive impairment conversion to Alzheimer disease. Diabetes 64, 1933-1940.

Williams, A. S., Kang, L., and Wasserman, D. H. (2015). The extracellular matrix and insulin resistance. Trends Endocrinol. Metab. 26, 357-366.

Won, K. B., Park, G. M., Lee, S. E., Cho, I. J., Kim, H. C., Lee, B. K., et al. (2018). Relationship of insulin resistance estimated by triglyceride glucose index to arterial stiffness. Lipids Health Dis. 17:268.

Wykretowicz, A., Guzik, P., Kasinowski, R., Krauze, T., Bartkowiak, G., Dziarmaga, M., et al. (2005). Augmentation index, pulse pressure amplification and superoxide anion production in patients with coronary artery disease. Int. J. Cardiol. 99, 289-294.

Wyssenbach, A., Quintela, T., Llavero, F., Zugaza, J. L., Matute, C., and Alberdi, E. (2016). Amyloid $\beta$-induced astrogliosis is mediated by $\beta 1$-integrin via NADPH oxidase 2 in Alzheimer's disease. Aging Cell 15, 1140-1152.

Xia, N., Daiber, A., Habermeier, A., Closs, E. I., Thum, T., Spanier, G., et al. (2010). Resveratrol reverses endothelial nitric-oxide synthase uncoupling in apolipoprotein E knockout mice. J. Pharmacol. Exp. Therap. 335, 149-154.

Yamada, M. (2002). Risk factors for cerebral amyloid angiopathy in the elderly. Ann. N. Y. Acad. Sci. 977, 37-44.

Yamada, M., Tsukagoshi, H., Otomo, E., and Hayakawa, M. (1987). Cerebral amyloid angiopathy in the aged. J. Neurol. 234, 371-376.

Yasmin, McEniery, C. M., Wallace, S., Dakham, Z., Pulsalkar, P., Maki-Petaja, K., et al. (2005). Matrix metalloproteinase-9 (MMP-9), MMP-2, and serum elastase activity are associated with systolic hypertension and arterial stiffness. Arterioscler. Thromb. Vasc. Biol. 25:372.

Yin, Y.-L., Zhu, M.-L., Wan, J., Zhang, C., Pan, G.-P., Lu, J.-X., et al. (2017). Traditional Chinese medicine xin-mai-jia recouples endothelial nitric oxide synthase to prevent atherosclerosis in vivo. Sci. Rep. 7, 1-12. 
Yoshii, S. R., Kuma, A., Akashi, T., Hara, T., Yamamoto, A., Kurikawa, Y., et al. (2016). Systemic analysis of Atg5-null mice rescued from neonatal lethality by transgenic ATG5 expression in neurons. Dev. Cell 39, 116-130.

Younger, S., Jang, H., Davies, H. A., Niemiec, M. J., Garcia, J. G. N., Nussinov, R., et al. (2020). Medin oligomer membrane pore formation: a potential mechanism of vascular dysfunction. Biophys. J. 118, 2769-2782.

Zhang, B., Yang, B., Du, L., and Guo, Y. (2020a). Nitric oxide donor andrographolide enhances humoral and cell-mediated immune responses. Cell Mol. Biol. 66, 176-180.

Zhang, S., Hu, X., Guo, S., Shi, L., He, Q., Zhang, P., et al. (2019). Myricetin ameliorated ischemia/reperfusion-induced brain endothelial permeability by improvement of eNOS uncoupling and activation eNOS/NO. J. Pharmacol. Sci. $140,62-72$.

Zhang, W., Qu, J., Liu, G.-H., and Belmonte, J. C. I. (2020b). The ageing epigenome and its rejuvenation. Nat. Rev. Mol. Cell Biol. 21, 137-150.
Zieman, S. J., Melenovsky, V., and Kass, D. A. (2005). Mechanisms, pathophysiology, and therapy of arterial stiffness. Arterioscler. Thromb. Vasc. Biol. 25, 932-943.

Conflict of Interest: The authors declare that the research was conducted in the absence of any commercial or financial relationships that could be construed as a potential conflict of interest.

Copyright ( $\odot 2021$ Hendrickx, Martinet, Van Dam and De Meyer. This is an openaccess article distributed under the terms of the Creative Commons Attribution License (CC BY). The use, distribution or reproduction in other forums is permitted, provided the original author(s) and the copyright owner(s) are credited and that the original publication in this journal is cited, in accordance with accepted academic practice. No use, distribution or reproduction is permitted which does not comply with these terms. 